\title{
Fast FluoroAlkylation of Proteins Uncovers Structure and Dynamics of Biological Macromolecules.
}

\author{
Lukáš Fojtík ${ }^{\dagger, \ddagger}$, Jan Fiala ${ }^{\dagger, \ddagger}$, Petr Pompach ${ }^{\dagger}$, Josef Chmelík ${ }^{\dagger, \ddagger}$, Václav Matoušek ${ }^{\top}$, Petr \\ Beier§, Zdeněk Kukačka* ${ }^{*} \dagger$ and Petr Novák* ${ }^{*} \dagger$ \\ †Institute of Microbiology of the Czech Academy of Sciences, 25250 Vestec, Czech Republic \\ $\ddagger$ Department of Biochemistry, Faculty of Science, Charles University, 12843 Prague, Czech Republic \\ †CF Plus Chemicals, 62100 Brno, Czech Republic \\ SInstitute of Organic Chemistry and Biochemistry of the Czech Academy of Sciences, 16610 Prague, Czech \\ Republic
}

KEYWORDS|: protein structure, conformational changes, radicals, trifluoromethylation, radical labeling, Togni reagents, fluoroalkylation, mass spectrometry, hypervalent iodine reagents, protein fingerprinting, epitope mapping, protein surface mapping, proteomics, interactomics

Table of contents

1, Comparison of zoomed MS spectra for all reactions of apo- and holomyoglobin S1 with Togni reagents

2, Extracted ion chromatograms from LC-MS analysis of myoglobin $\mathrm{S} 2$

3 , Structure of myoglobin with highlighted modified residues after reaction with reagent 1

4, Structure of myoglobin with highlighted modified residues after reaction with reagent 2

5, Quantification of aromatic residues of apo-and holomyoglobin for reagent 3 and $\mathbf{4}$

6 , Structure of myoglobin with highlighted modified residues after reaction with reagent 3

7 , Structure of myoglobin with highlighted modified residues after reaction with reagent 4

8, Quantification of hemoglobin modification using reagent 1

9, Quantification of haptoglobin modification using reagents $\mathbf{1}$ and $\mathbf{3}$

10 , Structure of haptoglobin-hemoglobin interaction interface with highlighted modified residues after reaction with reagent 3 11, Structure of WrbA with highlighted modified residues after reaction with reagent 3 


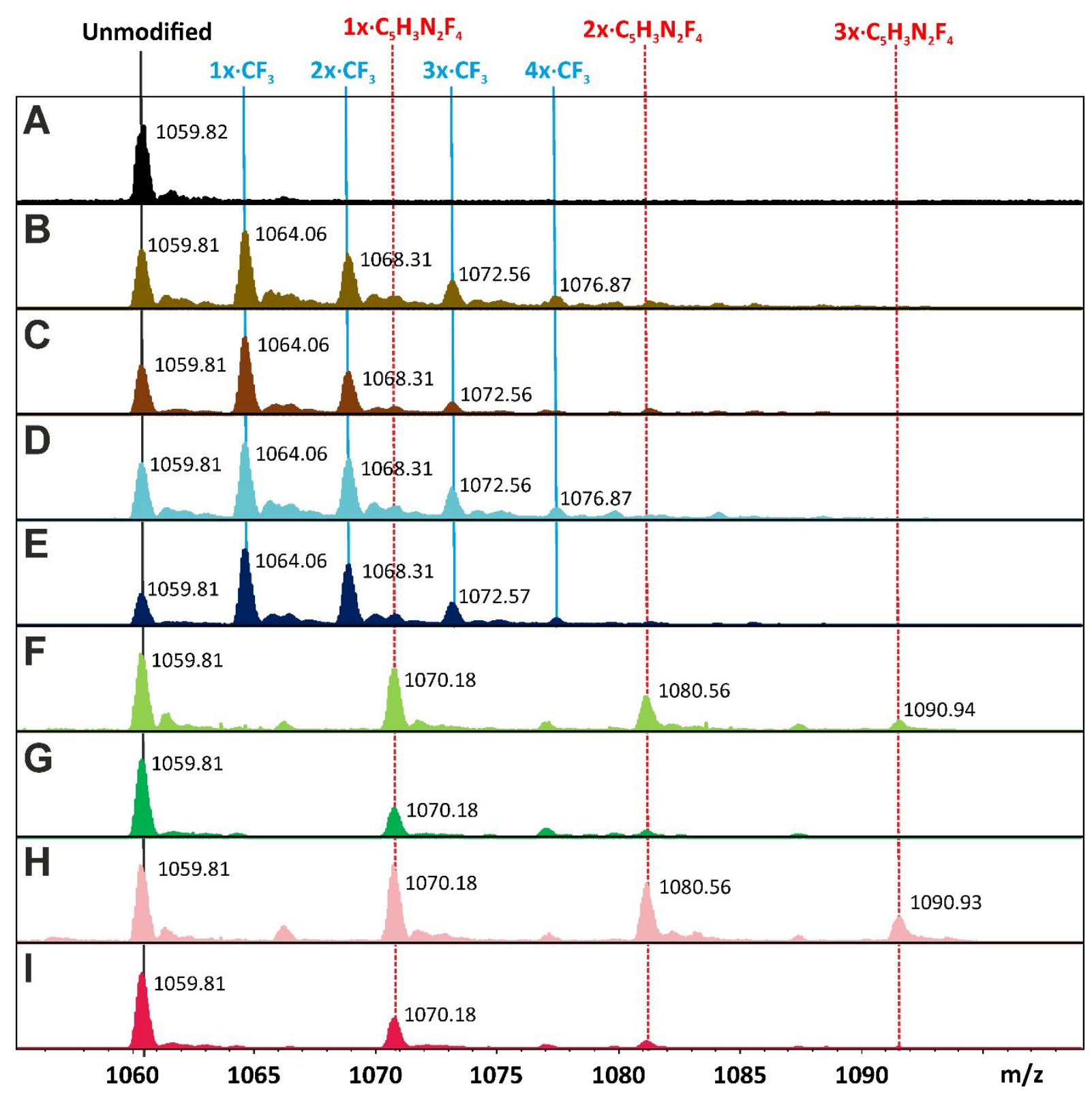

Figure S1: Comparison of MS spectra (zoom for 16+ charge state) for all reactions of apo- and holomyoglobin with Togni reagents $(\mathbf{1}, \mathbf{2} . \mathbf{3}, \mathbf{4})$ showing different products of reaction. Black line represents the unmodified myoglobin. Blue lines highlight myoglobin modified by trifluoromethyl radicals and red lines highlight myoglobin modified by imidazole-tetrafluoroethyl radicals. MS spectrum of unmodified apomyoglobin (A), apomyoglobin modified by reagent 1 (B), holomyoglobin modified by reagent 1 (C), apomyoglobin modified by reagent 3 (D), holomyoglobin modified by reagent $3(\mathrm{E})$, apomyoglobin modified by reagent $2(\mathrm{~F})$, holomyoglobin modified by reagent $2(\mathrm{G})$, apomyoglobin modified by reagent $4(\mathrm{H})$, holomyoglobin modified by reagent 4 (I) 


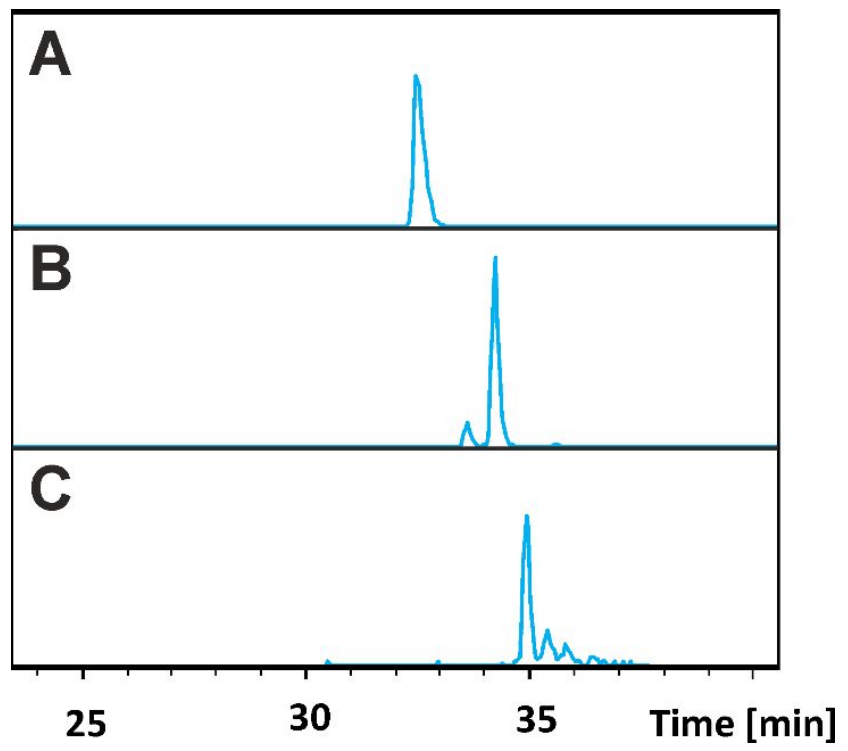

Figure S2: Extracted ion chromatograms of LC-MS analysis of myoglobin for unmodified (A), singly (B) and doubly (C) modified peptide 1-16. 


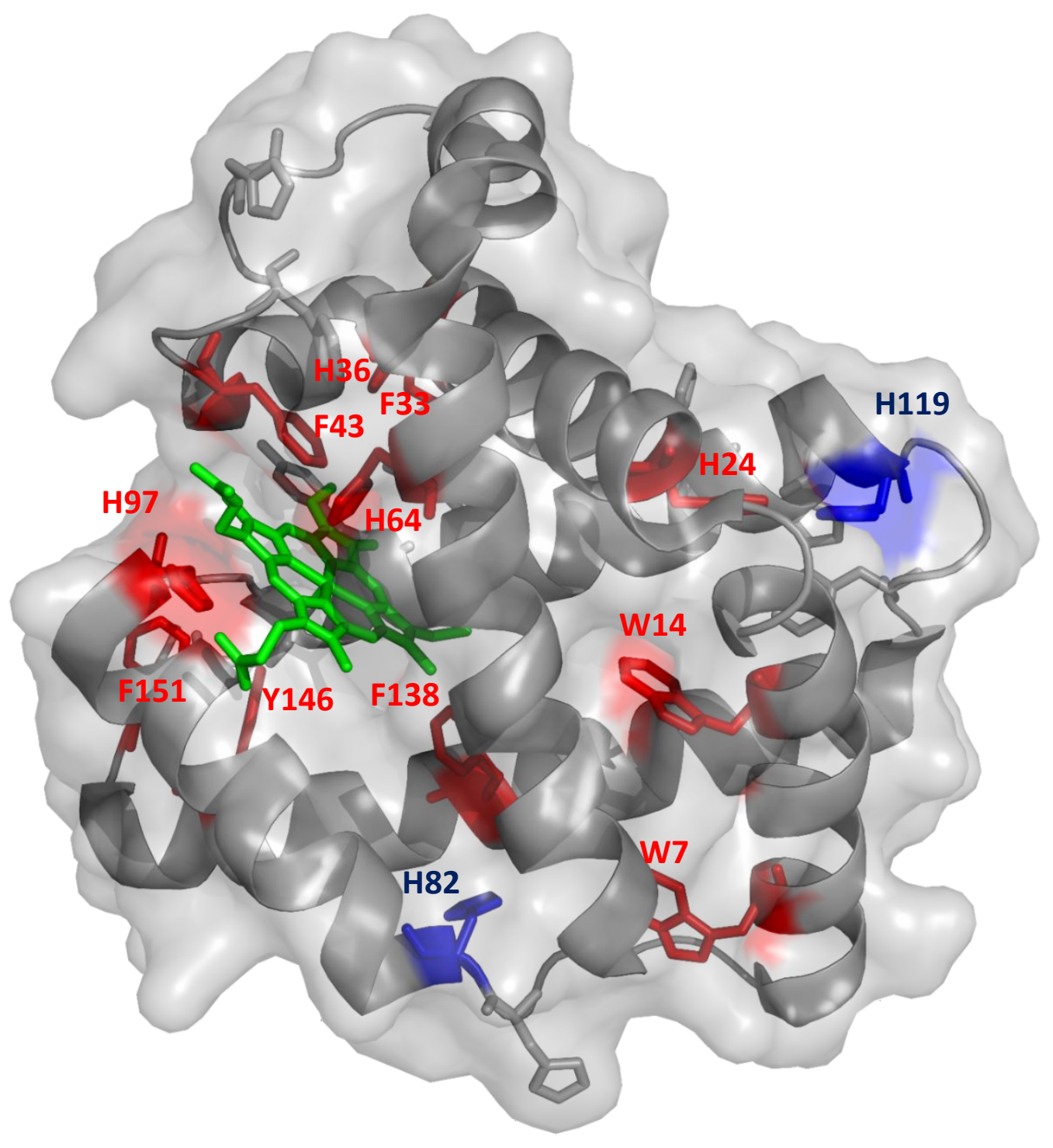

Figure S3: Structure of apo-/holomyoglobin with highlighted modified residues after reaction with reagent 1. Redmarked residues are less modified in holomyoglobin while the blue-marked ones are more modified in holomyoglobin. 


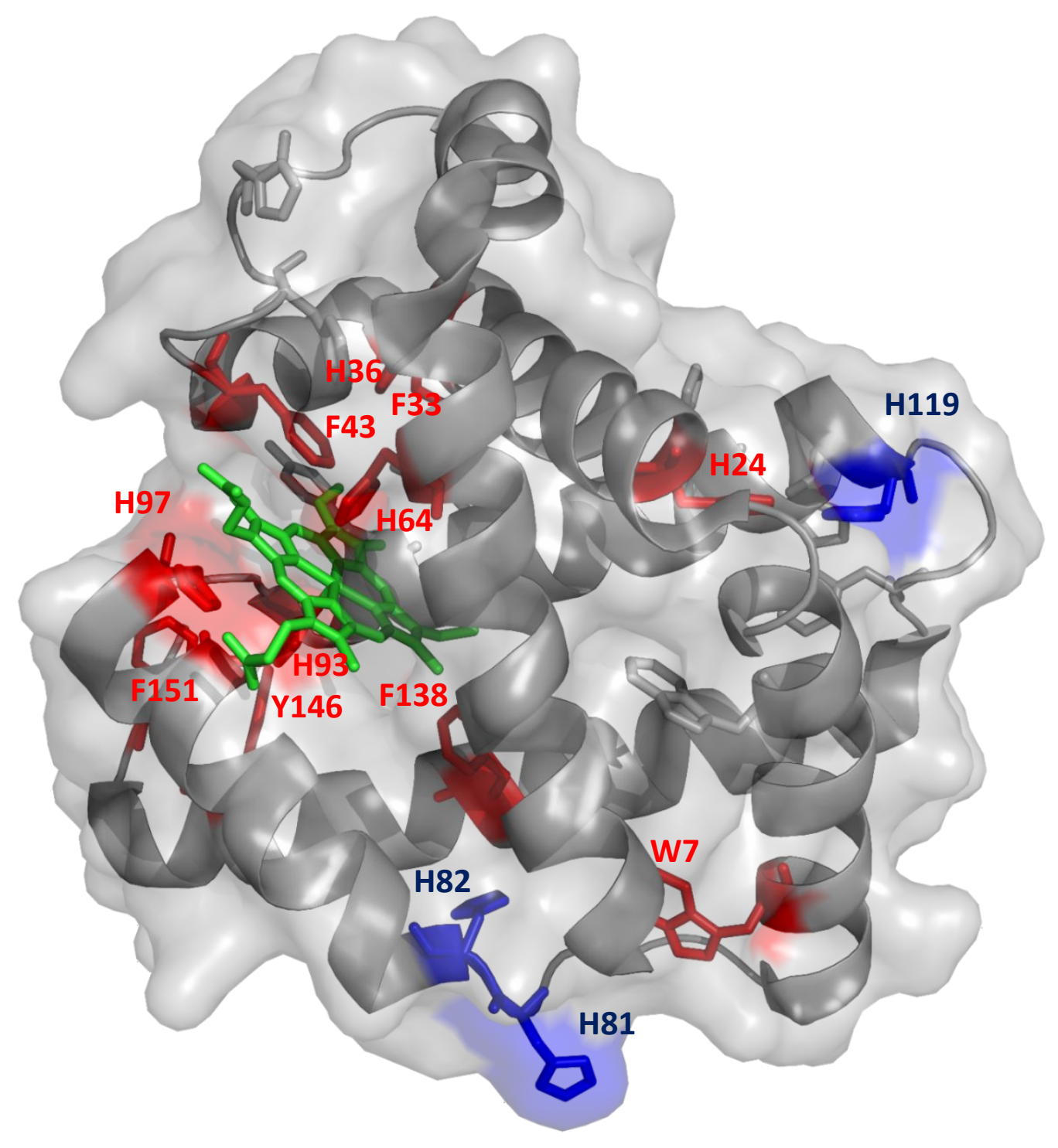

Figure S4: Structure of apo-/holomyoglobin with highlighted modified residues after reaction with reagent 2 . Redmarked residues are less modified in holomyoglobin while the blue-marked ones are more modified in holomyoglobin. 


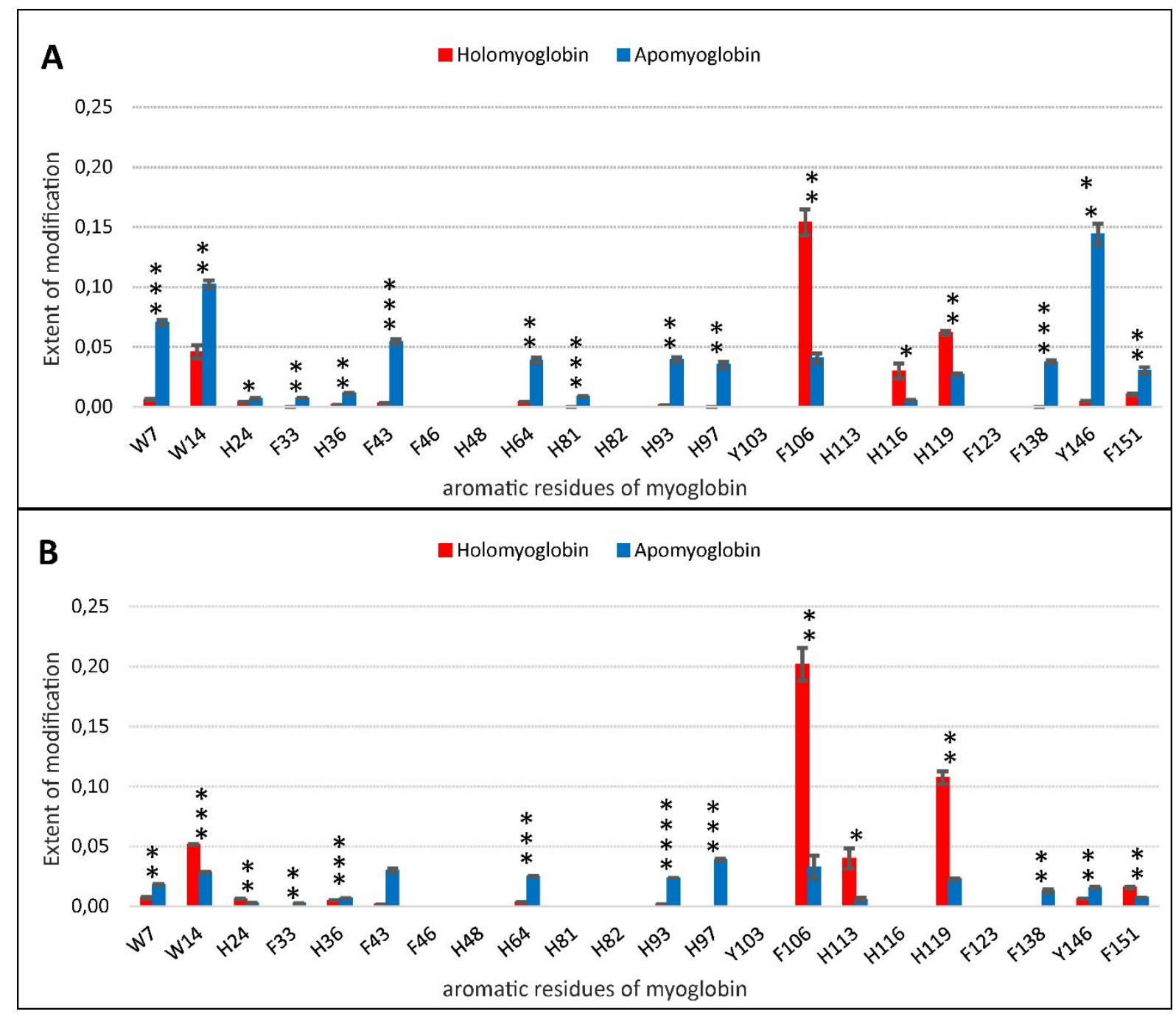

Figure S5: Quantification of aromatic residues of apo- and holomyoglobin for acid type Togni- $\mathrm{CF}_{2} \mathrm{CF}_{2} \operatorname{Im}$ reagent 3 (A) and for alcohol type Togni- $\mathrm{CF}_{2} \mathrm{CF}_{2} \mathrm{Im}$ reagent 4 (B). Red bars represent the extent of modification for holomyoglobin and blue bars for apomyoglobin, $\mathrm{P}$-value $(* * * \mathrm{P}<0.005$; ** $-\mathrm{P}<0.01 ; *-\mathrm{P}<0.05)$. 


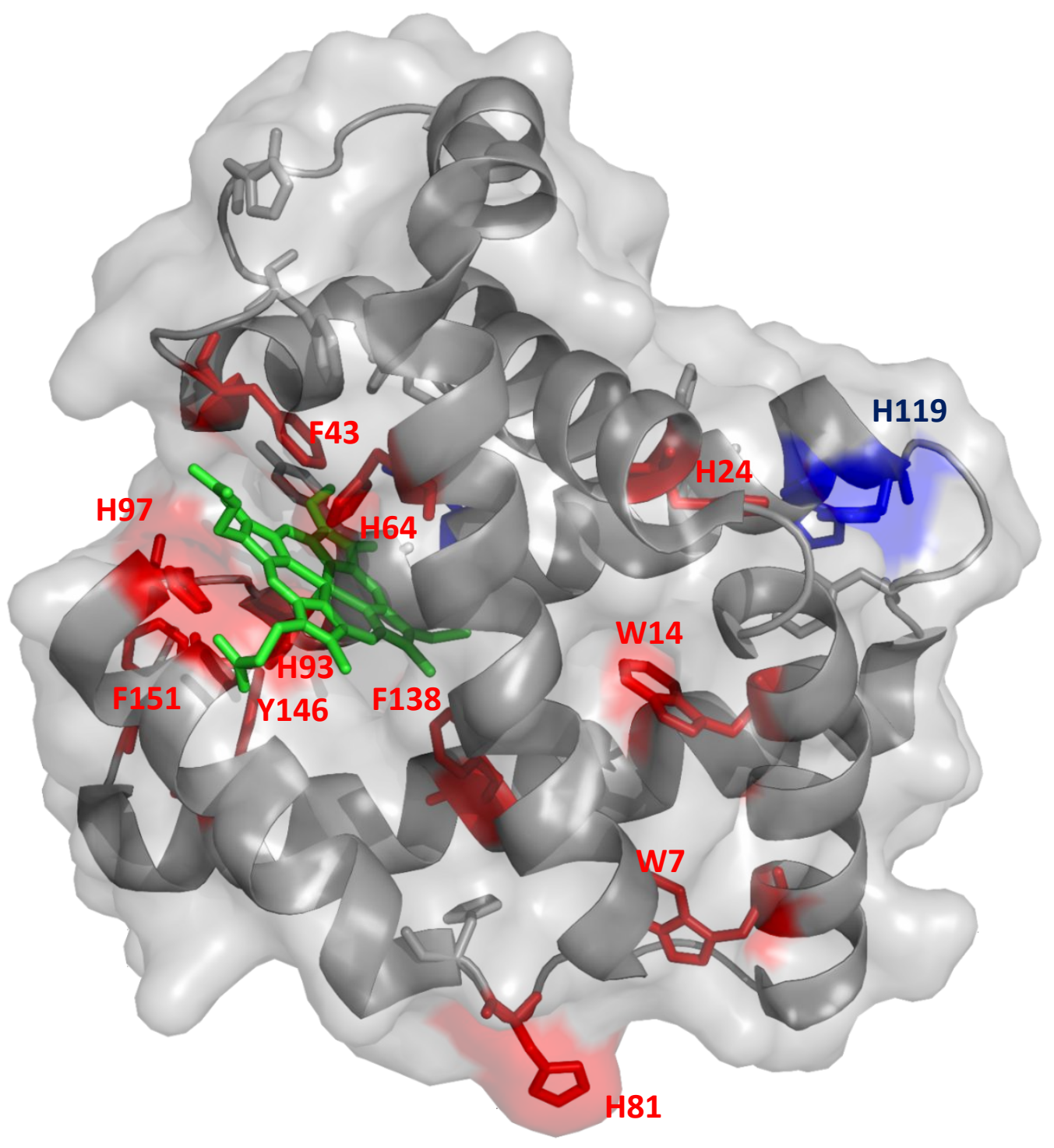

Figure S6: Structure of apo-/holomyoglobin with highlighted modified residues after reaction with reagent 3. Redmarked residues are less modified in holomyoglobin while the blue-marked ones are more modified in holomyoglobin. 


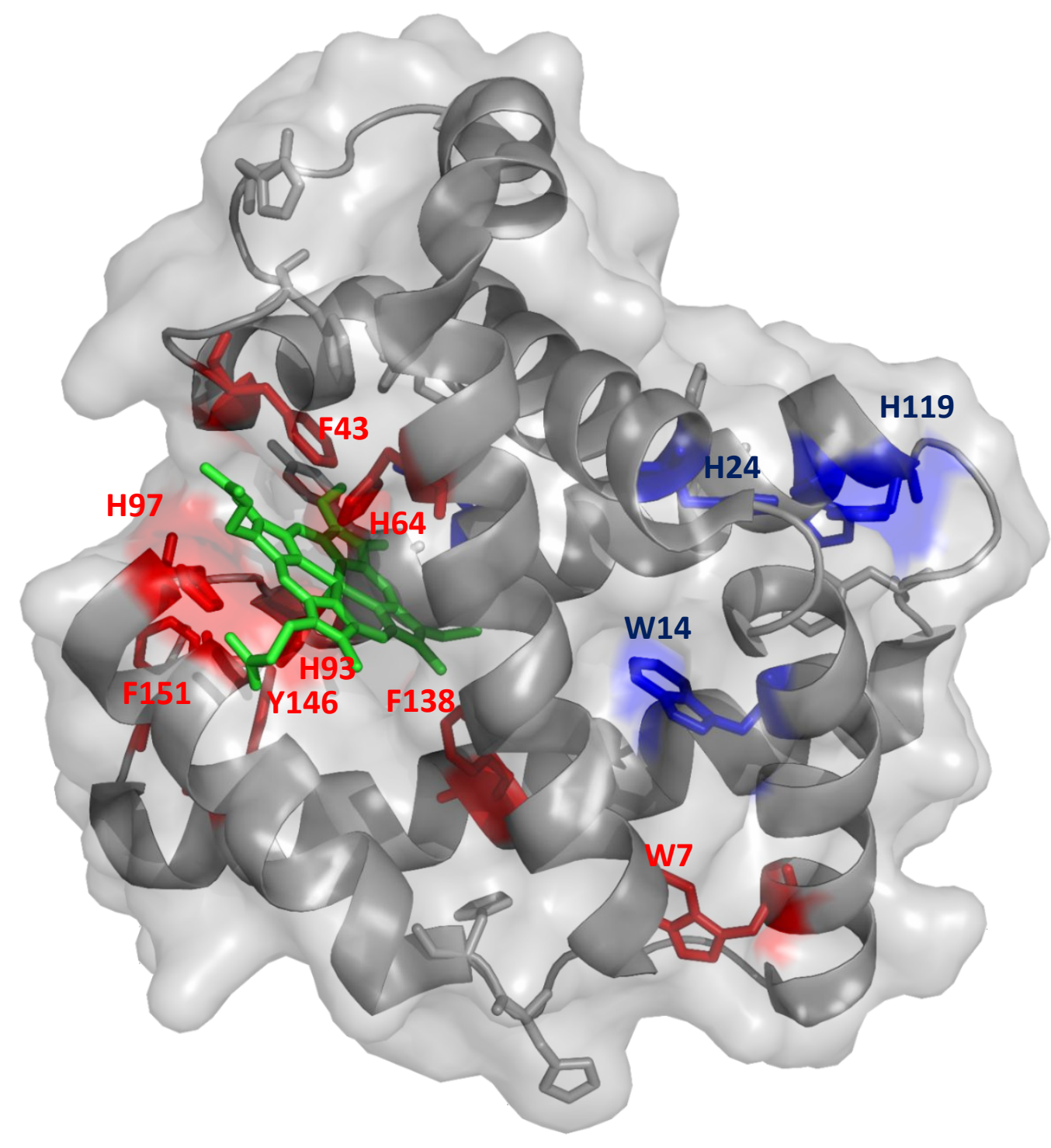

Figure S7: Structure of apo-/holomyoglobin with highlighted modified residues after reaction with reagent 4 . Redmarked residues are less modified in holomyoglobin while the blue-marked ones are more modified in holomyoglobin. 


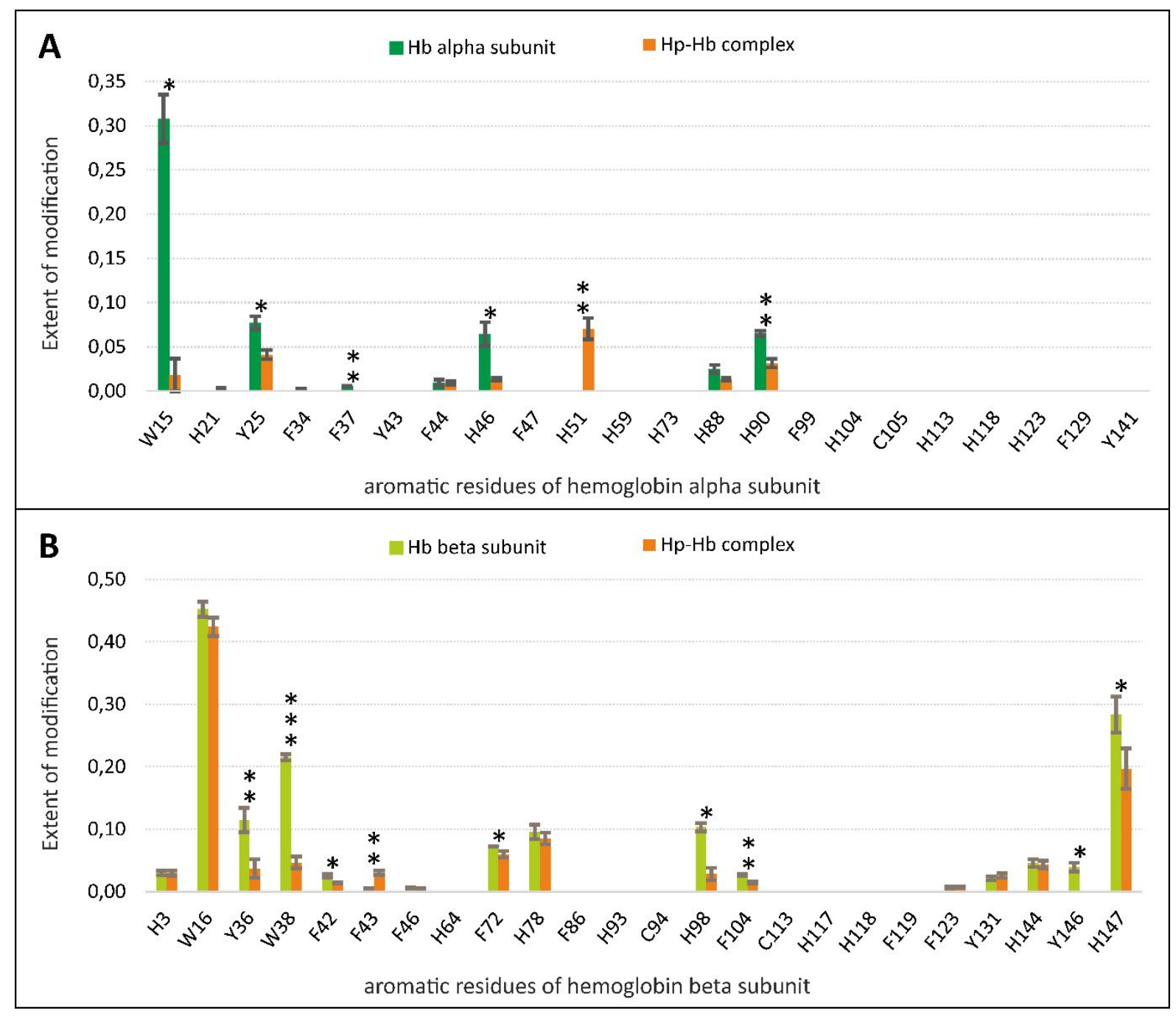

Figure S8: Quantification of modification for aromatic residues of $\mathrm{Hp}-\mathrm{Hb}$ complex for reagent 1. The upper graph (A) is quantification of $\mathrm{Hb} \alpha$ modification, the bottom graph $(\mathrm{B})$ is quantification of $\mathrm{Hb} \beta$ modification compare to $\mathrm{Hp}-\mathrm{Hb}$ complex. Orange columns show the extent of modification for $\mathrm{Hp}-\mathrm{Hb}$ complex and green columns show uncomplexed hemoglobin subunits, $\mathrm{P}$-value $(* * *-\mathrm{P}<0.005$; ** $-\mathrm{P}<0.01$; * $-\mathrm{P}<0.05)$. 


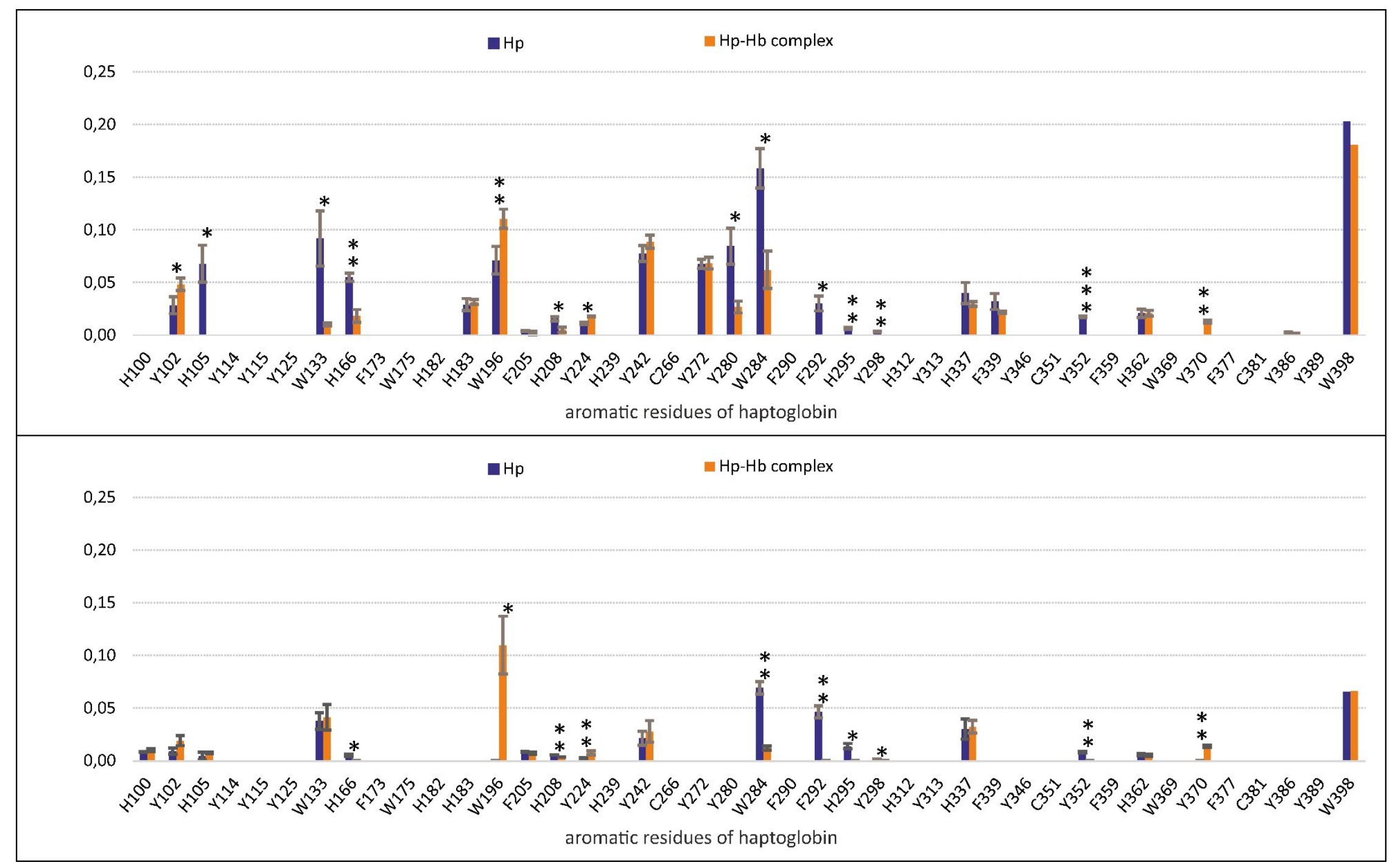

Figure S9: Quantification of modification for aromatic residues of Hp-Hb complex for reagent $\mathbf{1}$ (upper graph, A) and reagent $\mathbf{3}$ (bottom graph, B). Orange columns show the extent of modification for $\mathrm{Hp}-\mathrm{Hb}$ complex and purple columns uncomplexed Apt, P-value (*** - $\mathrm{P}<0.005$; ** - $\mathrm{P}<0.01$; * - P $<0.05$ ). 


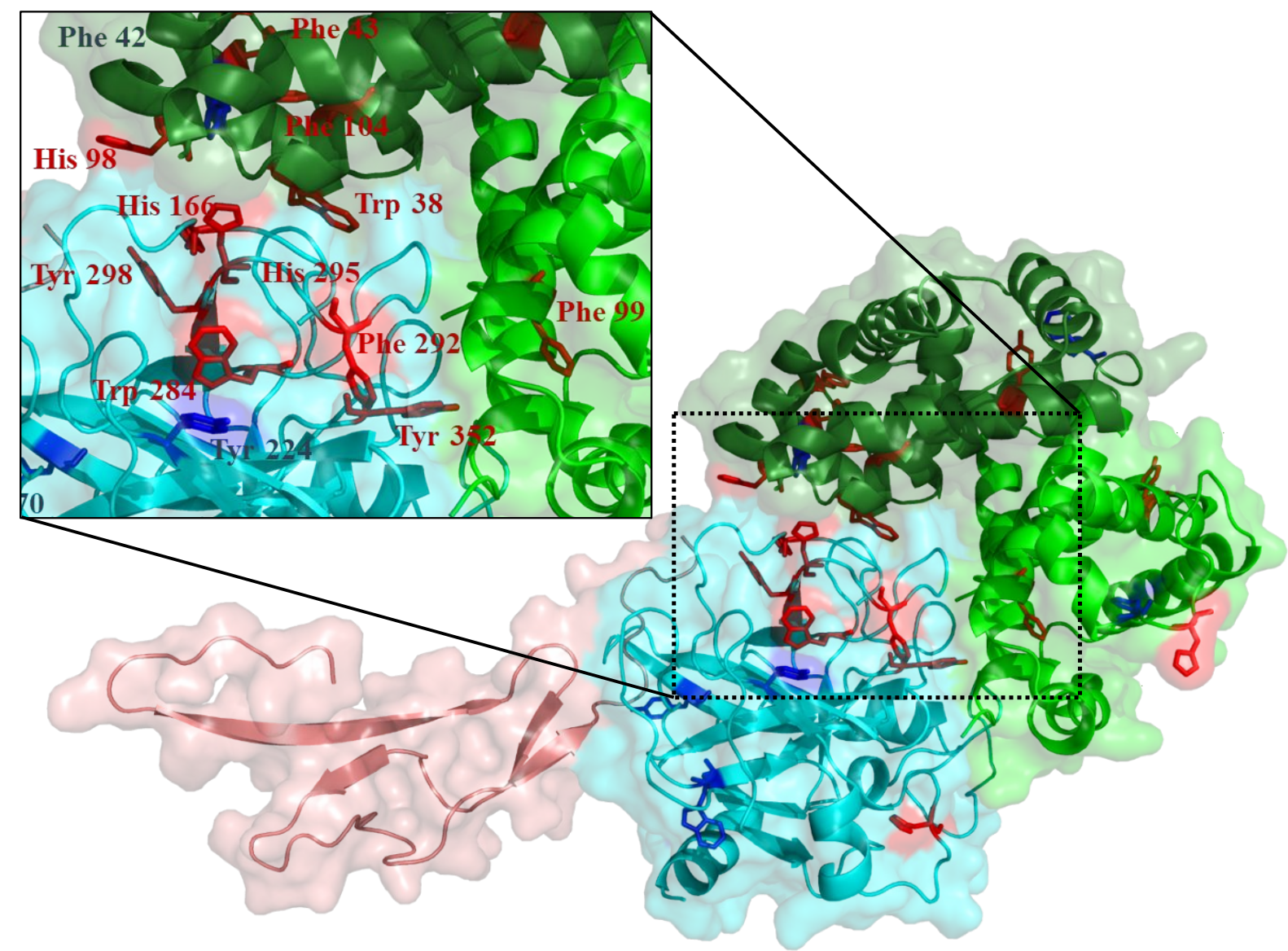

Figure S10: Structure of $\mathrm{Hp}-\mathrm{Hb}$ complex with highlighted modified residues after reaction with reagent 3. Red residues are less modified in $\mathrm{Hp}-\mathrm{Hb}$ complex while the blue ones are more modified in Hp-Hb complex. ZOOM - Interaction interface. 


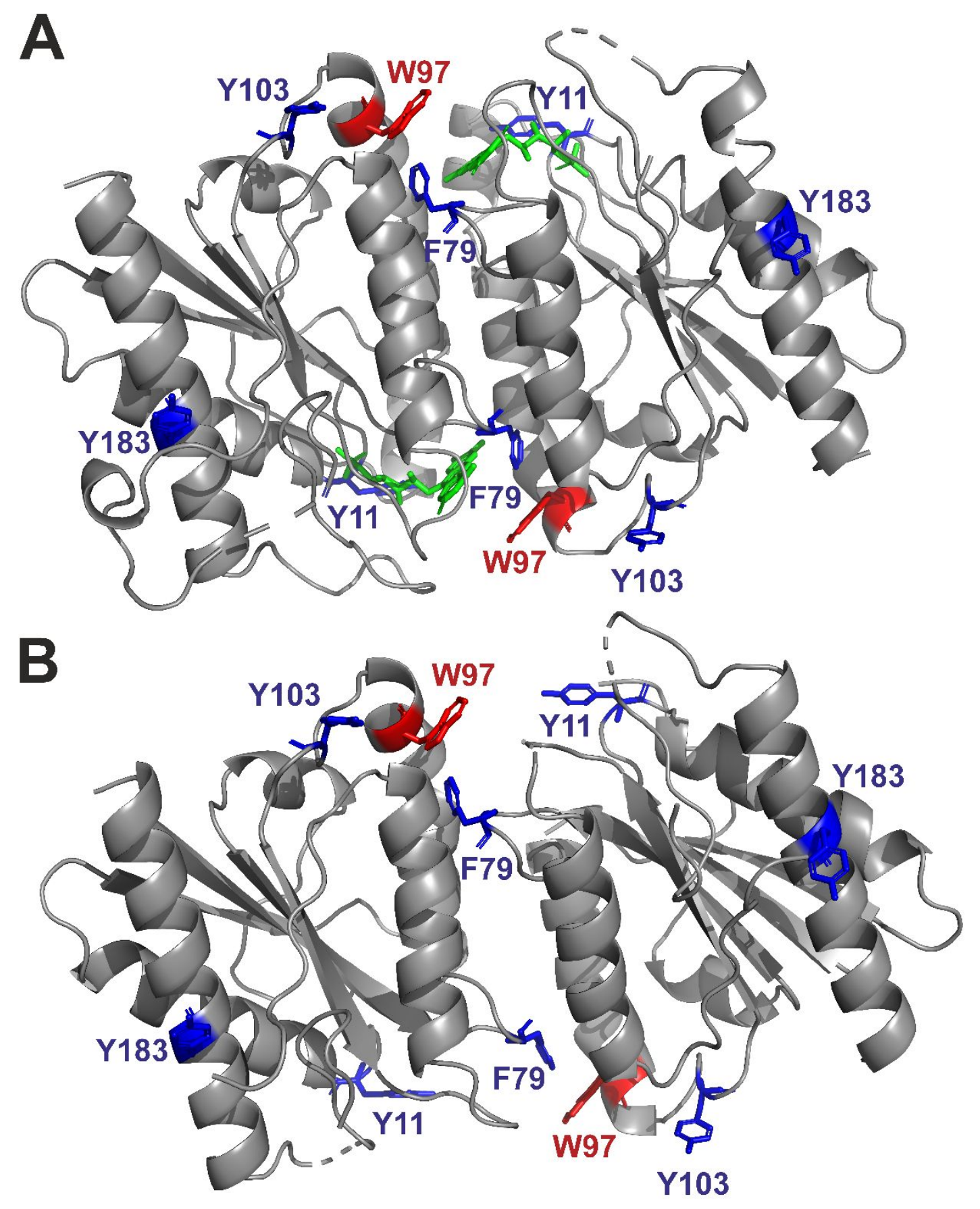

Figure S11: Structure of holoWrbA (A) 3ZHO and apoWrbA (B) 2RG1 with highlighted modified residues after reaction with reagent 3 . Red-marked residue is more modified in holoWrbA while the blue-marked ones are less modified in holoWrbA. Cofactor is highlighted in green. 
Table S1 Table of surface-accessible solvent area for apo- and holoWrbA protein structure. Absolute values represent accessible surface area in square angstroms for all atoms of each residue (columns on the right) or only for side chain atoms of residue (columns on the left, highlighted in red). Relative values are related to accessibility of theoretic residue in tripeptide Ala-X-ALA. Rows highlighted in yellow represent residues which were modified by reagent 3 and were statistically relevant. Not applicable (N/A) values belongs to residues that are missing in the crystal structure.

\begin{tabular}{|c|c|c|c|c|c|c|c|c|c|c|}
\hline \multirow{3}{*}{ Residue } & \multirow{3}{*}{ Subunit } & \multirow{3}{*}{ Number } & \multicolumn{4}{|c|}{ Area of residue side chain } & \multicolumn{4}{|c|}{ Area of all atoms } \\
\hline & & & \multicolumn{2}{|c|}{ ApoWrbA } & \multicolumn{2}{|c|}{ HoloWrbA } & \multicolumn{2}{|c|}{ ApoWrbA } & \multicolumn{2}{|c|}{ HoloWrbA } \\
\hline & & & $\begin{array}{c}\text { Absolute } \\
\AA^{2}\end{array}$ & $\begin{array}{c}\text { Relative } \\
\%\end{array}$ & $\begin{array}{c}\text { Absolute } \\
\AA^{2}\end{array}$ & $\begin{array}{c}\text { Relative } \\
\%\end{array}$ & $\begin{array}{c}\text { Absolute } \\
\AA^{2}\end{array}$ & $\begin{array}{c}\text { Relative } \\
\%\end{array}$ & $\begin{array}{c}\text { Absolute } \\
\AA^{2}\end{array}$ & $\begin{array}{c}\text { Relative } \\
\%\end{array}$ \\
\hline ALA & A & 1 & 37.67 & 54.30 & 4.92 & 7.10 & 37.67 & 34.90 & 22.55 & 20.90 \\
\hline LYS & A & 2 & 86.75 & 53.10 & 72.96 & 44.70 & 86.75 & 43.20 & 72.96 & 36.30 \\
\hline VAL & A & 3 & 0.00 & 0.00 & 0.00 & 0.00 & 0.00 & 0.00 & 0.00 & 0.00 \\
\hline LEU & A & 4 & 0.02 & 0.00 & 0.00 & 0.00 & 0.02 & 0.00 & 0.00 & 0.00 \\
\hline VAL & A & 5 & 0.00 & 0.00 & 0.00 & 0.00 & 0.00 & 0.00 & 0.00 & 0.00 \\
\hline LEU & A & 6 & 0.00 & 0.00 & 0.00 & 0.00 & 0.00 & 0.00 & 0.00 & 0.00 \\
\hline TYR & A & 7 & 0.10 & 0.10 & 0.22 & 0.10 & 0.10 & 0.00 & 0.22 & 0.10 \\
\hline TYR & A & 8 & 10.99 & 6.20 & 4.55 & 2.60 & 10.99 & 5.20 & 4.55 & 2.10 \\
\hline SER & A & 9 & 1.73 & 2.20 & 0.00 & 0.00 & 3.14 & 2.70 & 3.53 & 3.00 \\
\hline MET & A & 10 & 78.52 & 50.10 & 10.02 & -99.90 & 82.35 & 42.40 & 10.02 & -99.90 \\
\hline TYR & A & 11 & 111.60 & 62.90 & 70.25 & 39.60 & 121.64 & 57.20 & 84.78 & 39.80 \\
\hline GLY & A & 12 & 2.39 & 7.40 & 2.80 & 8.70 & 4.46 & 5.60 & 5.48 & 6.80 \\
\hline HIS & A & 13 & 13.71 & 9.30 & 2.48 & 1.70 & 13.71 & 7.50 & 2.50 & 1.40 \\
\hline ILE & A & 14 & 0.00 & 0.00 & 0.00 & 0.00 & 0.00 & 0.00 & 0.00 & 0.00 \\
\hline GLU & A & 15 & 15.91 & 11.80 & 18.12 & 13.40 & 15.91 & 9.20 & 18.12 & 10.50 \\
\hline THR & A & 16 & 54.92 & 54.00 & 44.59 & 43.80 & 56.85 & 40.80 & 45.67 & 32.80 \\
\hline MET & A & 17 & 0.00 & 0.00 & 0.00 & 0.00 & 0.00 & 0.00 & 0.00 & 0.00 \\
\hline ALA & A & 18 & 0.00 & 0.00 & 0.05 & 0.10 & 0.00 & 0.00 & 0.05 & 0.00 \\
\hline ARG & A & 19 & 95.53 & 47.50 & 98.86 & 49.10 & 101.09 & 42.30 & 104.92 & 43.90 \\
\hline ALA & A & 20 & 3.71 & 5.30 & 4.65 & 6.70 & 5.44 & 5.00 & 5.45 & 5.00 \\
\hline VAL & A & 21 & 0.00 & 0.00 & 0.00 & 0.00 & 0.00 & 0.00 & 0.00 & 0.00 \\
\hline ALA & A & 22 & 9.76 & 14.10 & 12.01 & 17.30 & 10.41 & 9.60 & 14.03 & 13.00 \\
\hline GLU & A & 23 & 91.20 & 67.70 & 94.17 & 69.90 & 93.33 & 54.20 & 94.98 & 55.10 \\
\hline GLY & A & 24 & 0.06 & 0.20 & 0.23 & 0.70 & 0.06 & 0.10 & 0.23 & 0.30 \\
\hline ALA & A & 25 & 0.00 & 0.00 & 0.00 & 0.00 & 0.00 & 0.00 & 0.00 & 0.00 \\
\hline SER & A & 26 & 45.86 & 58.70 & 48.47 & 62.10 & 70.34 & 60.40 & 70.78 & 60.80 \\
\hline LYS & A & 27 & 95.66 & 58.60 & 93.40 & 57.20 & 123.39 & 61.40 & 120.65 & 60.10 \\
\hline VAL & A & 28 & 23.19 & 20.30 & 24.02 & 21.00 & 26.39 & 17.40 & 25.46 & 16.80 \\
\hline ASP & A & 29 & 122.61 & 119.40 & 79.85 & 77.80 & 135.91 & 96.80 & 93.58 & 66.70 \\
\hline GLY & A & 30 & 34.31 & 106.10 & 32.75 & 101.30 & 50.43 & 63.00 & 53.19 & 66.40 \\
\hline ALA & A & 31 & 0.00 & 0.00 & 0.00 & 0.00 & 19.25 & 17.80 & 16.16 & 15.00 \\
\hline GLU & A & 32 & 98.26 & 72.90 & 97.30 & 72.20 & 98.26 & 57.00 & 97.69 & 56.70 \\
\hline VAL & A & 33 & 5.94 & 5.20 & 8.67 & 7.60 & 35.50 & 23.40 & 36.33 & 24.00 \\
\hline VAL & A & 34 & 38.69 & 33.90 & 41.72 & 36.50 & 38.69 & 25.60 & 41.72 & 27.50 \\
\hline VAL & A & 35 & 19.44 & 17.00 & 7.91 & 6.90 & 28.67 & 18.90 & 15.62 & 10.30 \\
\hline LYS & A & 36 & 32.97 & 20.20 & 36.21 & 22.20 & 32.97 & 16.40 & 36.21 & 18.00 \\
\hline ARG & A & 37 & 44.49 & 22.10 & 57.57 & 28.60 & 44.49 & 18.60 & 57.57 & 24.10 \\
\hline
\end{tabular}




\begin{tabular}{|c|c|c|c|c|c|c|c|c|c|c|}
\hline VAL & A & 38 & 0.00 & 0.00 & 0.00 & 0.00 & 1.35 & 0.90 & 1.81 & 1.20 \\
\hline PRO & A & 39 & 54.83 & 45.70 & 54.08 & 45.10 & 55.84 & 41.00 & 54.73 & 40.20 \\
\hline GLU & A & 40 & 83.91 & 62.30 & 26.13 & 19.40 & 108.37 & 62.90 & 49.07 & 28.50 \\
\hline THR & A & 41 & 54.81 & 53.90 & 37.46 & 36.80 & 114.37 & 82.10 & 62.63 & 45.00 \\
\hline MET & $A$ & 42 & N/A & N/A & 48.07 & 30.70 & N/A & N/A & 54.62 & 28.10 \\
\hline PRO & A & 43 & $\mathrm{~N} / \mathrm{A}$ & N/A & 73.23 & 61.10 & N/A & $\mathrm{N} / \mathrm{A}$ & 73.26 & 53.80 \\
\hline PRO & $A$ & 44 & N/A & N/A & 111.36 & 92.90 & N/A & N/A & 114.26 & 83.90 \\
\hline GLN & A & 45 & $\mathrm{~N} / \mathrm{A}$ & N/A & 71.19 & 50.50 & $\mathrm{~N} / \mathrm{A}$ & $\mathrm{N} / \mathrm{A}$ & 77.60 & 43.50 \\
\hline LEU & $A$ & 46 & N/A & N/A & 106.08 & 75.20 & N/A & N/A & 108.28 & 60.60 \\
\hline PHE & A & 47 & $\mathrm{~N} / \mathrm{A}$ & $\mathrm{N} / \mathrm{A}$ & 24.34 & 14.80 & $\mathrm{~N} / \mathrm{A}$ & $\mathrm{N} / \mathrm{A}$ & 24.34 & 12.20 \\
\hline GLU & A & 48 & N/A & N/A & 53.92 & 40.00 & N/A & N/A & 70.21 & 40.80 \\
\hline LYS & A & 49 & N/A & N/A & 58.79 & 36.00 & N/A & N/A & 90.10 & 44.90 \\
\hline ALA & A & 50 & $\mathrm{~N} / \mathrm{A}$ & N/A & 31.51 & 45.40 & N/A & N/A & 46.95 & 43.50 \\
\hline GLY & A & 51 & N/A & N/A & 32.98 & 102.00 & N/A & N/A & 49.79 & 62.20 \\
\hline GLY & $A$ & 52 & 28.16 & 87.10 & 0.00 & 0.00 & 115.17 & 143.80 & 17.76 & 22.20 \\
\hline LYS & $A$ & 53 & 111.15 & 68.10 & 90.19 & 55.20 & 120.74 & 60.10 & 91.35 & 45.50 \\
\hline THR & $A$ & 54 & 111.40 & 109.50 & 107.65 & 105.90 & 116.39 & 83.60 & 121.20 & 87.00 \\
\hline GLN & A & 55 & 42.51 & 30.20 & 8.79 & 6.20 & 65.83 & 36.90 & 19.09 & 10.70 \\
\hline THR & A & 56 & 47.82 & 47.00 & 106.11 & 104.30 & 75.63 & 54.30 & 128.05 & 91.90 \\
\hline ALA & $A$ & 57 & 3.06 & 4.40 & 0.77 & 1.10 & 4.00 & 3.70 & 3.10 & 2.90 \\
\hline PRO & A & 58 & 84.26 & 70.30 & 75.93 & 63.30 & 84.28 & 61.90 & 75.93 & 55.80 \\
\hline VAL & A & 59 & 51.70 & 45.20 & 48.07 & 42.10 & 71.73 & 47.40 & 68.78 & 45.40 \\
\hline ALA & A & 60 & 0.00 & 0.00 & 0.00 & 0.00 & 1.20 & 1.10 & 2.75 & 2.50 \\
\hline THR & A & 61 & 74.69 & 73.40 & 66.66 & 65.50 & 74.69 & 53.60 & 66.66 & 47.90 \\
\hline PRO & A & 62 & 26.18 & 21.80 & 16.76 & 14.00 & 26.18 & 19.20 & 16.76 & 12.30 \\
\hline GLN & A & 63 & 131.53 & 93.30 & 114.12 & 80.90 & 136.80 & 76.60 & 119.75 & 67.10 \\
\hline GLU & A & 64 & 43.07 & 32.00 & 28.62 & 21.20 & 43.95 & 25.50 & 28.86 & 16.80 \\
\hline LEU & A & 65 & 0.00 & 0.00 & 0.14 & 0.10 & 0.00 & 0.00 & 0.14 & 0.10 \\
\hline ALA & A & 66 & 21.50 & 31.00 & 21.92 & 31.60 & 35.48 & 32.90 & 35.08 & 32.50 \\
\hline ASP & A & 67 & 78.24 & 76.20 & 70.87 & 69.00 & 88.35 & 62.90 & 81.06 & 57.70 \\
\hline TYR & A & 68 & 17.65 & 9.90 & 12.02 & 6.80 & 18.33 & 8.60 & 12.53 & 5.90 \\
\hline ASP & A & 69 & 33.89 & 33.00 & 30.88 & 30.10 & 35.47 & 25.30 & 31.90 & 22.70 \\
\hline ALA & A & 70 & 0.00 & 0.00 & 0.00 & 0.00 & 0.00 & 0.00 & 0.00 & 0.00 \\
\hline ILE & A & 71 & 0.00 & 0.00 & 0.00 & 0.00 & 0.00 & 0.00 & 0.00 & 0.00 \\
\hline ILE & A & 72 & 0.00 & 0.00 & 0.00 & 0.00 & 0.00 & 0.00 & 0.00 & 0.00 \\
\hline PHE & A & 73 & 0.27 & 0.20 & 1.96 & 1.20 & 0.27 & 0.10 & 1.96 & 1.00 \\
\hline GLY & $A$ & 74 & 0.00 & 0.00 & 0.00 & 0.00 & 0.00 & 0.00 & 0.00 & 0.00 \\
\hline THR & A & 75 & 0.37 & 0.40 & 0.44 & 0.40 & 0.37 & 0.30 & 0.44 & 0.30 \\
\hline PRO & A & 76 & 11.28 & 9.40 & 0.00 & 0.00 & 11.28 & 8.30 & 0.00 & 0.00 \\
\hline THR & A & 77 & 0.19 & 0.20 & 0.00 & 0.00 & 6.13 & 4.40 & 0.00 & 0.00 \\
\hline ARG & A & 78 & 71.30 & 35.40 & 6.89 & 3.40 & 71.45 & 29.90 & 6.89 & 2.90 \\
\hline PHE & A & 79 & 12.95 & 7.90 & 2.39 & 1.50 & 14.06 & 7.00 & 2.39 & 1.20 \\
\hline GLY & A & 80 & 0.00 & 0.00 & 0.00 & 0.00 & 4.27 & 5.30 & 0.20 & 0.20 \\
\hline ASN & A & 81 & 6.21 & 5.80 & 0.70 & 0.70 & 6.21 & 4.30 & 0.70 & 0.50 \\
\hline MET & A & 82 & 6.07 & 3.90 & 0.24 & 0.20 & 6.20 & 3.20 & 0.24 & 0.10 \\
\hline
\end{tabular}




\begin{tabular}{|c|c|c|c|c|c|c|c|c|c|c|}
\hline SER & A & 83 & 4.88 & 6.30 & 0.00 & 0.00 & 4.88 & 4.20 & 0.00 & 0.00 \\
\hline GLY & A & 84 & 8.73 & 27.00 & 1.16 & 3.60 & 10.72 & 13.40 & 1.33 & 1.70 \\
\hline GLN & $A$ & 85 & 32.66 & 23.20 & 9.81 & 7.00 & 33.90 & 19.00 & 11.40 & 6.40 \\
\hline MET & A & 86 & 0.20 & 0.10 & 0.54 & 0.30 & 0.20 & 0.10 & 0.54 & 0.30 \\
\hline ARG & A & 87 & 28.03 & 13.90 & 0.58 & 0.30 & 28.10 & 11.80 & 0.58 & 0.20 \\
\hline THR & A & 88 & 44.58 & 43.80 & 25.71 & 25.30 & 44.58 & 32.00 & 26.25 & 18.90 \\
\hline PHE & $A$ & 89 & 3.52 & 2.10 & 3.79 & 2.30 & 4.08 & 2.00 & 4.06 & 2.00 \\
\hline LEU & A & 90 & 4.12 & 2.90 & 3.55 & 2.50 & 12.20 & 6.80 & 3.55 & 2.00 \\
\hline ASP & $A$ & 91 & 34.94 & 34.00 & 8.37 & 8.20 & 50.07 & 35.70 & 20.61 & 14.70 \\
\hline GLN & A & 92 & 90.95 & 64.50 & 86.93 & 61.70 & 106.66 & 59.80 & 98.65 & 55.30 \\
\hline THR & A & 93 & 0.88 & 0.90 & 0.56 & 0.50 & 1.31 & 0.90 & 0.56 & 0.40 \\
\hline GLY & $A$ & 94 & 30.81 & 95.30 & 19.90 & 61.50 & 39.98 & 49.90 & 28.79 & 35.90 \\
\hline GLY & A & 95 & 37.99 & 117.50 & 38.70 & 119.70 & 58.53 & 73.10 & 56.88 & 71.00 \\
\hline LEU & $A$ & 96 & 9.20 & 6.50 & 19.22 & 13.60 & 10.40 & 5.80 & 20.65 & 11.60 \\
\hline TRP & A & 97 & 66.69 & 31.60 & 88.28 & 41.80 & 76.92 & 30.80 & 98.67 & 39.60 \\
\hline ALA & $A$ & 98 & 49.06 & 70.70 & 47.49 & 68.40 & 81.97 & 75.90 & 79.10 & 73.30 \\
\hline SER & A & 99 & 56.39 & 72.20 & 57.45 & 73.50 & 87.25 & 74.90 & 87.19 & 74.80 \\
\hline GLY & $A$ & 100 & 27.02 & 83.60 & 24.38 & 75.40 & 42.61 & 53.20 & 38.17 & 47.70 \\
\hline ALA & A & 101 & 19.52 & 28.10 & 19.20 & 27.70 & 30.74 & 28.50 & 25.99 & 24.10 \\
\hline LEU & A & 102 & 0.43 & 0.30 & 2.80 & 2.00 & 1.22 & 0.70 & 3.30 & 1.80 \\
\hline TYR & A & 103 & 37.37 & 21.10 & 36.25 & 20.40 & 55.91 & 26.30 & 54.37 & 25.60 \\
\hline GLY & $A$ & 104 & 8.99 & 27.80 & 9.52 & 29.40 & 25.65 & 32.00 & 26.68 & 33.30 \\
\hline LYS & $A$ & 105 & 35.98 & 22.00 & 42.22 & 25.90 & 35.98 & 17.90 & 42.22 & 21.00 \\
\hline LEU & $A$ & 106 & 2.09 & 1.50 & 2.94 & 2.10 & 2.09 & 1.20 & 3.06 & 1.70 \\
\hline ALA & A & 107 & 0.84 & 1.20 & 0.00 & 0.00 & 1.20 & 1.10 & 0.00 & 0.00 \\
\hline SER & A & 108 & 0.00 & 0.00 & 0.00 & 0.00 & 0.00 & 0.00 & 0.00 & 0.00 \\
\hline VAL & $A$ & 109 & 0.10 & 0.10 & 0.00 & 0.00 & 0.10 & 0.10 & 0.00 & 0.00 \\
\hline PHE & $A$ & 110 & 0.00 & 0.00 & 0.00 & 0.00 & 0.00 & 0.00 & 0.00 & 0.00 \\
\hline SER & A & 111 & 0.00 & 0.00 & 0.00 & 0.00 & 0.00 & 0.00 & 0.00 & 0.00 \\
\hline SER & A & 112 & 0.42 & 0.50 & 0.00 & 0.00 & 0.42 & 0.40 & 0.00 & 0.00 \\
\hline THR & A & 113 & 18.52 & 18.20 & 0.00 & 0.00 & 25.74 & 18.50 & 0.00 & 0.00 \\
\hline GLY & $A$ & 114 & 27.88 & 86.20 & 4.64 & 14.30 & 68.00 & 84.90 & 4.94 & 6.20 \\
\hline THR & $A$ & 115 & N/A & N/A & 61.19 & 60.20 & N/A & N/A & 83.85 & 60.20 \\
\hline GLY & $A$ & 116 & $\mathrm{~N} / \mathrm{A}$ & N/A & 11.14 & 34.50 & N/A & N/A & 16.24 & 20.30 \\
\hline GLY & A & 117 & 0.78 & 2.40 & 0.33 & 1.00 & 24.47 & 30.60 & 1.04 & 1.30 \\
\hline GLY & $A$ & 118 & 0.00 & 0.00 & 0.00 & 0.00 & 0.00 & 0.00 & 0.00 & 0.00 \\
\hline GLN & A & 119 & 27.21 & 19.30 & 28.77 & 20.40 & 27.21 & 15.20 & 28.77 & 16.10 \\
\hline GLU & $A$ & 120 & 1.16 & 0.90 & 2.87 & 2.10 & 1.16 & 0.70 & 2.87 & 1.70 \\
\hline GLN & A & 121 & 19.87 & 14.10 & 15.29 & 10.80 & 19.87 & 11.10 & 15.34 & 8.60 \\
\hline THR & $A$ & 122 & 0.00 & 0.00 & 0.00 & 0.00 & 0.00 & 0.00 & 0.00 & 0.00 \\
\hline ILE & A & 123 & 0.00 & 0.00 & 0.00 & 0.00 & 0.00 & 0.00 & 0.00 & 0.00 \\
\hline THR & A & 124 & 16.36 & 16.10 & 17.50 & 17.20 & 18.32 & 13.20 & 23.40 & 16.80 \\
\hline SER & A & 125 & 16.26 & 20.80 & 10.52 & 13.50 & 17.45 & 15.00 & 10.69 & 9.20 \\
\hline THR & A & 126 & 0.29 & 0.30 & 0.26 & 0.30 & 0.29 & 0.20 & 0.26 & 0.20 \\
\hline TRP & A & 127 & 3.93 & 1.90 & 3.91 & 1.90 & 3.93 & 1.60 & 3.91 & 1.60 \\
\hline
\end{tabular}




\begin{tabular}{|c|c|c|c|c|c|c|c|c|c|c|}
\hline THR & $A$ & 128 & 11.41 & 11.20 & 4.01 & 3.90 & 11.41 & 8.20 & 4.21 & 3.00 \\
\hline THR & $A$ & 129 & 28.98 & 28.50 & 0.23 & 0.20 & 29.47 & 21.20 & 0.23 & 0.20 \\
\hline LEU & $A$ & 130 & 0.68 & 0.50 & 1.59 & 1.10 & 0.68 & 0.40 & 1.59 & 0.90 \\
\hline ALA & $A$ & 131 & 0.00 & 0.00 & 0.00 & 0.00 & 0.00 & 0.00 & 0.00 & 0.00 \\
\hline HIS & $A$ & 132 & 1.47 & 1.00 & 0.94 & 0.60 & 2.53 & 1.40 & 2.05 & 1.10 \\
\hline HIS & $A$ & 133 & 17.84 & 12.10 & 5.28 & 3.60 & 22.52 & 12.30 & 9.75 & 5.30 \\
\hline GLY & $A$ & 134 & 0.00 & 0.00 & 0.00 & 0.00 & 0.07 & 0.10 & 0.11 & 0.10 \\
\hline MET & $A$ & 135 & 0.00 & 0.00 & 0.80 & 0.50 & 0.00 & 0.00 & 0.80 & 0.40 \\
\hline VAL & $A$ & 136 & 0.83 & 0.70 & 3.03 & 2.60 & 0.83 & 0.50 & 3.03 & 2.00 \\
\hline ILE & $A$ & 137 & 0.23 & 0.20 & 0.00 & 0.00 & 0.23 & 0.10 & 0.00 & 0.00 \\
\hline VAL & $A$ & 138 & 0.00 & 0.00 & 0.00 & 0.00 & 0.00 & 0.00 & 0.00 & 0.00 \\
\hline PRO & $A$ & 139 & 0.00 & 0.00 & 0.14 & 0.10 & 0.00 & 0.00 & 0.33 & 0.20 \\
\hline ILE & $A$ & 140 & 4.30 & 3.10 & 6.88 & 5.00 & 4.30 & 2.50 & 7.30 & 4.20 \\
\hline GLY & $A$ & 141 & 0.00 & 0.00 & 0.00 & 0.00 & 5.44 & 6.80 & 4.49 & 5.60 \\
\hline TYR & $A$ & 142 & 74.76 & 42.10 & 59.85 & 33.70 & 101.93 & 47.90 & 78.28 & 36.80 \\
\hline ALA & $A$ & 143 & 18.66 & 26.90 & 0.67 & 1.00 & 70.72 & 65.50 & 12.60 & 11.70 \\
\hline ALA & A & 144 & N/A & N/A & 53.93 & 77.70 & N/A & N/A & 61.01 & 56.50 \\
\hline GLN & $A$ & 145 & N/A & N/A & 65.66 & 46.60 & N/A & N/A & 80.35 & 45.00 \\
\hline GLU & $A$ & 146 & N/A & N/A & 135.67 & 100.70 & N/A & N/A & 160.23 & 93.00 \\
\hline LEU & $A$ & 147 & N/A & N/A & 86.16 & 61.10 & N/A & N/A & 97.82 & 54.80 \\
\hline PHE & A & 148 & N/A & N/A & 15.31 & 9.30 & N/A & N/A & 27.64 & 13.90 \\
\hline ASP & A & 149 & N/A & N/A & 56.57 & 55.10 & N/A & $\mathrm{N} / \mathrm{A}$ & 87.42 & 62.30 \\
\hline VAL & $A$ & 150 & N/A & N/A & 43.54 & 38.10 & N/A & N/A & 44.34 & 29.30 \\
\hline SER & $A$ & 151 & N/A & N/A & 84.53 & 108.20 & N/A & N/A & 102.00 & 87.60 \\
\hline GLN & $A$ & 152 & N/A & N/A & 73.02 & 51.80 & N/A & $\mathrm{N} / \mathrm{A}$ & 103.95 & 58.20 \\
\hline VAL & A & 153 & N/A & N/A & 6.66 & 5.80 & $\mathrm{~N} / \mathrm{A}$ & N/A & 64.53 & 42.60 \\
\hline ARG & A & 154 & N/A & N/A & N/A & $\mathrm{N} / \mathrm{A}$ & N/A & N/A & N/A & N/A \\
\hline GLY & A & 155 & N/A & N/A & N/A & $\mathrm{N} / \mathrm{A}$ & $\mathrm{N} / \mathrm{A}$ & N/A & N/A & N/A \\
\hline GLY & A & 156 & 28.17 & 87.10 & N/A & $\mathrm{N} / \mathrm{A}$ & 71.85 & 89.70 & N/A & N/A \\
\hline THR & A & 157 & 0.00 & 0.00 & 1.01 & 1.00 & 7.58 & 5.40 & 38.09 & 27.40 \\
\hline PRO & $A$ & 158 & 8.28 & 6.90 & 0.00 & 0.00 & 8.67 & 6.40 & 0.00 & 0.00 \\
\hline TYR & A & 159 & 0.00 & 0.00 & 0.00 & 0.00 & 0.00 & 0.00 & 0.00 & 0.00 \\
\hline GLY & $A$ & 160 & 0.00 & 0.00 & 0.00 & 0.00 & 0.04 & 0.10 & 0.69 & 0.90 \\
\hline ALA & A & 161 & 0.66 & 1.00 & 1.41 & 2.00 & 0.66 & 0.60 & 1.41 & 1.30 \\
\hline THR & A & 162 & 6.13 & 6.00 & 21.00 & 20.70 & 11.55 & 8.30 & 27.65 & 19.90 \\
\hline THR & A & 163 & 0.72 & 0.70 & 0.01 & 0.00 & 0.76 & 0.50 & 0.01 & 0.00 \\
\hline ILE & $A$ & 164 & 101.65 & 73.70 & 54.25 & 39.30 & 101.65 & 58.00 & 54.26 & 31.00 \\
\hline ALA & A & 165 & 2.10 & 3.00 & 0.00 & 0.00 & 33.98 & 31.50 & 0.00 & 0.00 \\
\hline GLY & A & 166 & N/A & N/A & 14.82 & 45.80 & $\mathrm{~N} / \mathrm{A}$ & N/A & 16.46 & 20.50 \\
\hline GLY & A & 167 & N/A & N/A & 25.77 & 79.70 & N/A & N/A & 72.30 & 90.30 \\
\hline ASP & A & 168 & N/A & N/A & 87.54 & 85.30 & N/A & N/A & 118.16 & 84.20 \\
\hline GLY & A & 169 & N/A & N/A & 13.92 & 43.10 & N/A & N/A & 25.77 & 32.20 \\
\hline SER & A & 170 & 95.76 & 122.60 & 62.77 & 80.40 & 139.43 & 119.70 & 80.05 & 68.70 \\
\hline ARG & $A$ & 171 & 102.57 & 51.00 & 94.36 & 46.90 & 103.44 & 43.30 & 94.45 & 39.60 \\
\hline GLN & $A$ & 172 & 124.68 & 88.40 & 100.49 & 71.30 & 135.12 & 75.70 & 110.47 & 61.90 \\
\hline
\end{tabular}




\begin{tabular}{|c|c|c|c|c|c|c|c|c|c|c|}
\hline PRO & A & 173 & 2.16 & 1.80 & 0.98 & 0.80 & 11.69 & 8.60 & 14.45 & 10.60 \\
\hline SER & A & 174 & 27.30 & 34.90 & 37.52 & 48.00 & 27.30 & 23.40 & 37.52 & 32.20 \\
\hline GLN & $A$ & 175 & 117.51 & 83.30 & 100.53 & 71.30 & 122.06 & 68.40 & 107.41 & 60.20 \\
\hline GLU & A & 176 & 121.64 & 90.30 & 47.48 & 35.20 & 122.25 & 71.00 & 50.28 & 29.20 \\
\hline GLU & A & 177 & 23.98 & 17.80 & 24.80 & 18.40 & 24.07 & 14.00 & 24.87 & 14.40 \\
\hline LEU & A & 178 & 14.62 & 10.40 & 15.54 & 11.00 & 14.62 & 8.20 & 15.54 & 8.70 \\
\hline SER & $A$ & 179 & 51.98 & 66.60 & 0.00 & 0.00 & 58.16 & 49.90 & 0.44 & 0.40 \\
\hline ILE & A & 180 & 67.17 & 48.70 & 43.08 & 31.20 & 67.17 & 38.40 & 43.08 & 24.60 \\
\hline ALA & $A$ & 181 & 0.00 & 0.00 & 0.00 & 0.00 & 0.00 & 0.00 & 0.00 & 0.00 \\
\hline ARG & A & 182 & 55.27 & 27.50 & 26.31 & 13.10 & 55.97 & 23.40 & 27.12 & 11.40 \\
\hline TYR & A & 183 & 64.45 & 36.30 & 11.12 & 6.30 & 65.40 & 30.70 & 12.03 & 5.70 \\
\hline GLN & $A$ & 184 & 0.00 & 0.00 & 0.00 & 0.00 & 0.00 & 0.00 & 0.00 & 0.00 \\
\hline GLY & $A$ & 185 & 0.00 & 0.00 & 0.00 & 0.00 & 0.00 & 0.00 & 0.00 & 0.00 \\
\hline GLU & $A$ & 186 & 65.20 & 48.40 & 50.88 & 37.80 & 67.53 & 39.20 & 52.71 & 30.60 \\
\hline TYR & $A$ & 187 & 30.86 & 17.40 & 34.82 & 19.60 & 32.05 & 15.10 & 36.13 & 17.00 \\
\hline VAL & $A$ & 188 & 0.00 & 0.00 & 0.00 & 0.00 & 0.00 & 0.00 & 0.00 & 0.00 \\
\hline ALA & $A$ & 189 & 0.00 & 0.00 & 0.00 & 0.00 & 0.00 & 0.00 & 0.00 & 0.00 \\
\hline GLY & $A$ & 190 & 18.27 & 56.50 & 19.06 & 58.90 & 25.94 & 32.40 & 28.09 & 35.10 \\
\hline LEU & $A$ & 191 & 14.26 & 10.10 & 18.87 & 13.40 & 15.34 & 8.60 & 20.04 & 11.20 \\
\hline ALA & $A$ & 192 & 0.00 & 0.00 & 0.00 & 0.00 & 0.00 & 0.00 & 0.00 & 0.00 \\
\hline VAL & A & 193 & 41.92 & 36.70 & 32.66 & 28.60 & 50.74 & 33.50 & 36.38 & 24.00 \\
\hline LYS & $A$ & 194 & 100.62 & 61.60 & 98.38 & 60.20 & 118.99 & 59.30 & 117.68 & 58.60 \\
\hline LEU & $A$ & 195 & 12.15 & 8.60 & 10.80 & 7.70 & 16.75 & 9.40 & 19.28 & 10.80 \\
\hline ASN & $A$ & 196 & 43.80 & 41.20 & 44.02 & 41.40 & 98.67 & 68.50 & 76.78 & 53.30 \\
\hline GLY & $A$ & 197 & N/A & N/A & 34.68 & 107.30 & N/A & N/A & 70.22 & 87.70 \\
\hline ALA & B & 1 & 3.76 & 5.40 & 5.33 & 7.70 & 18.32 & 17.00 & 18.74 & 17.40 \\
\hline LYS & B & 2 & 88.59 & 54.20 & 76.58 & 46.90 & 88.59 & 44.10 & 76.58 & 38.10 \\
\hline VAL & B & 3 & 0.00 & 0.00 & 0.00 & 0.00 & 0.00 & 0.00 & 0.00 & 0.00 \\
\hline LEU & B & 4 & 0.00 & 0.00 & 0.00 & 0.00 & 0.00 & 0.00 & 0.00 & 0.00 \\
\hline VAL & B & 5 & 0.00 & 0.00 & 0.00 & 0.00 & 0.00 & 0.00 & 0.00 & 0.00 \\
\hline LEU & B & 6 & 0.00 & 0.00 & 0.00 & 0.00 & 0.00 & 0.00 & 0.00 & 0.00 \\
\hline TYR & B & 7 & 1.81 & 1.00 & 3.32 & 1.90 & 1.81 & 0.90 & 3.32 & 1.60 \\
\hline TYR & B & 8 & 22.59 & 12.70 & 4.49 & 2.50 & 22.59 & 10.60 & 4.49 & 2.10 \\
\hline SER & B & 9 & 0.00 & 0.00 & 0.00 & 0.00 & 5.17 & 4.40 & 1.58 & 1.40 \\
\hline MET & B & 10 & 68.66 & 43.80 & 8.49 & -99.90 & 98.24 & 50.60 & 8.49 & -99.90 \\
\hline TYR & B & 11 & 128.95 & 72.70 & 64.68 & 36.50 & 157.51 & 74.00 & 79.47 & 37.40 \\
\hline GLY & B & 12 & 15.52 & 48.00 & 2.26 & 7.00 & 21.81 & 27.20 & 5.92 & 7.40 \\
\hline HIS & B & 13 & 28.39 & 19.30 & 37.88 & 25.80 & 28.39 & 15.50 & 37.88 & 20.70 \\
\hline ILE & B & 14 & 0.00 & 0.00 & 0.00 & 0.00 & 0.00 & 0.00 & 0.00 & 0.00 \\
\hline GLU & B & 15 & 24.49 & 18.20 & 40.55 & 30.10 & 24.57 & 14.30 & 43.77 & 25.40 \\
\hline THR & B & 16 & 47.97 & 47.20 & 37.07 & 36.40 & 48.94 & 35.10 & 37.84 & 27.20 \\
\hline MET & B & 17 & 0.00 & 0.00 & 0.00 & 0.00 & 0.00 & 0.00 & 0.00 & 0.00 \\
\hline ALA & B & 18 & 0.16 & 0.20 & 0.81 & 1.20 & 0.16 & 0.20 & 0.81 & 0.80 \\
\hline ARG & B & 19 & 113.45 & 56.40 & 159.15 & 79.10 & 119.71 & 50.10 & 160.19 & 67.10 \\
\hline ALA & B & 20 & 8.99 & 13.00 & 1.04 & 1.50 & 9.82 & 9.10 & 1.08 & 1.00 \\
\hline
\end{tabular}




\begin{tabular}{|c|c|c|c|c|c|c|c|c|c|c|}
\hline VAL & B & 21 & 0.00 & 0.00 & 0.00 & 0.00 & 0.00 & 0.00 & 0.00 & 0.00 \\
\hline ALA & B & 22 & 12.69 & 18.30 & 12.15 & 17.50 & 13.77 & 12.80 & 13.04 & 12.10 \\
\hline GLU & B & 23 & 77.44 & 57.50 & 73.11 & 54.30 & 78.00 & 45.30 & 76.78 & 44.60 \\
\hline GLY & B & 24 & 0.00 & 0.00 & 0.00 & 0.00 & 0.00 & 0.00 & 0.00 & 0.00 \\
\hline ALA & B & 25 & 0.00 & 0.00 & 0.00 & 0.00 & 0.00 & 0.00 & 0.00 & 0.00 \\
\hline SER & B & 26 & 41.39 & 53.00 & 44.96 & 57.60 & 66.83 & 57.40 & 69.94 & 60.00 \\
\hline LYS & B & 27 & 82.59 & 50.60 & 100.40 & 61.50 & 105.67 & 52.60 & 122.73 & 61.10 \\
\hline VAL & B & 28 & 19.63 & 17.20 & 23.96 & 21.00 & 24.47 & 16.20 & 26.54 & 17.50 \\
\hline ASP & B & 29 & 121.93 & 118.70 & 122.21 & 119.00 & 130.75 & 93.10 & 132.88 & 94.70 \\
\hline GLY & B & 30 & 31.66 & 97.90 & 29.85 & 92.30 & 52.46 & 65.50 & 46.42 & 57.90 \\
\hline ALA & B & 31 & 0.00 & 0.00 & 0.00 & 0.00 & 19.68 & 18.20 & 16.38 & 15.20 \\
\hline GLU & B & 32 & 100.44 & 74.50 & 117.72 & 87.40 & 100.44 & 58.30 & 118.07 & 68.50 \\
\hline VAL & B & 33 & 8.37 & 7.30 & 5.17 & 4.50 & 37.85 & 25.00 & 37.47 & 24.70 \\
\hline VAL & B & 34 & 45.17 & 39.50 & 51.09 & 44.70 & 45.17 & 29.80 & 51.09 & 33.70 \\
\hline VAL & B & 35 & 26.47 & 23.20 & 34.62 & 30.30 & 36.60 & 24.20 & 44.85 & 29.60 \\
\hline LYS & B & 36 & 39.56 & 24.20 & 38.22 & 23.40 & 39.56 & 19.70 & 38.22 & 19.00 \\
\hline ARG & B & 37 & 65.52 & 32.60 & 43.11 & 21.40 & 65.52 & 27.40 & 43.11 & 18.10 \\
\hline VAL & B & 38 & 0.00 & 0.00 & 0.00 & 0.00 & 0.85 & 0.60 & 2.02 & 1.30 \\
\hline PRO & B & 39 & 57.28 & 47.80 & 54.98 & 45.90 & 60.92 & 44.70 & 55.53 & 40.80 \\
\hline GLU & B & 40 & 85.67 & 63.60 & 27.01 & 20.00 & 107.06 & 62.20 & 49.15 & 28.50 \\
\hline THR & B & 41 & 105.70 & 103.90 & 35.14 & 34.60 & 127.85 & 91.80 & 59.96 & 43.10 \\
\hline MET & B & 42 & $\mathrm{~N} / \mathrm{A}$ & $\mathrm{N} / \mathrm{A}$ & 47.50 & 30.30 & $\mathrm{~N} / \mathrm{A}$ & $\mathrm{N} / \mathrm{A}$ & 52.66 & 27.10 \\
\hline PRO & B & 43 & $\mathrm{~N} / \mathrm{A}$ & $\mathrm{N} / \mathrm{A}$ & 72.37 & 60.40 & $\mathrm{~N} / \mathrm{A}$ & $\mathrm{N} / \mathrm{A}$ & 72.38 & 53.20 \\
\hline PRO & B & 44 & N/A & N/A & 107.63 & 89.80 & N/A & N/A & 108.98 & 80.10 \\
\hline GLN & B & 45 & $\mathrm{~N} / \mathrm{A}$ & $\mathrm{N} / \mathrm{A}$ & 142.71 & 101.20 & $\mathrm{~N} / \mathrm{A}$ & $\mathrm{N} / \mathrm{A}$ & 152.40 & 85.40 \\
\hline LEU & B & 46 & $\mathrm{~N} / \mathrm{A}$ & $\mathrm{N} / \mathrm{A}$ & 96.69 & 68.50 & N/A & N/A & 98.39 & 55.10 \\
\hline PHE & B & 47 & N/A & N/A & 14.41 & 8.80 & N/A & N/A & 14.41 & 7.20 \\
\hline GLU & B & 48 & $\mathrm{~N} / \mathrm{A}$ & $\mathrm{N} / \mathrm{A}$ & 76.54 & 56.80 & $\mathrm{~N} / \mathrm{A}$ & $\mathrm{N} / \mathrm{A}$ & 92.01 & 53.40 \\
\hline LYS & B & 49 & N/A & N/A & 84.96 & 52.00 & N/A & N/A & 110.51 & 55.00 \\
\hline ALA & B & 50 & N/A & N/A & 32.98 & 47.50 & N/A & N/A & 46.62 & 43.20 \\
\hline GLY & B & 51 & N/A & N/A & 33.77 & 104.40 & N/A & N/A & 51.75 & 64.60 \\
\hline GLY & B & 52 & N/A & N/A & 0.00 & 0.00 & N/A & N/A & 18.30 & 22.80 \\
\hline LYS & B & 53 & N/A & $\mathrm{N} / \mathrm{A}$ & 101.58 & 62.20 & N/A & $\mathrm{N} / \mathrm{A}$ & 101.58 & 50.60 \\
\hline THR & B & 54 & N/A & N/A & 83.76 & 82.40 & $\mathrm{~N} / \mathrm{A}$ & N/A & 97.98 & 70.40 \\
\hline GLN & B & 55 & 49.26 & 34.90 & 7.53 & 5.30 & 109.12 & 61.10 & 14.66 & 8.20 \\
\hline THR & B & 56 & 97.51 & 95.90 & 94.28 & 92.70 & 120.33 & 86.40 & 118.77 & 85.30 \\
\hline ALA & B & 57 & 11.80 & 17.00 & 16.65 & 24.00 & 13.67 & 12.70 & 20.91 & 19.40 \\
\hline PRO & B & 58 & 76.64 & 63.90 & 82.87 & 69.10 & 76.64 & 56.30 & 82.87 & 60.90 \\
\hline VAL & B & 59 & 51.68 & 45.20 & 46.99 & 41.10 & 71.49 & 47.20 & 66.91 & 44.20 \\
\hline ALA & B & 60 & 0.00 & 0.00 & 0.00 & 0.00 & 1.97 & 1.80 & 2.55 & 2.40 \\
\hline THR & B & 61 & 62.62 & 61.60 & 67.70 & 66.60 & 62.62 & 45.00 & 67.70 & 48.60 \\
\hline PRO & B & 62 & 22.53 & 18.80 & 16.89 & 14.10 & 22.53 & 16.60 & 16.89 & 12.40 \\
\hline GLN & B & 63 & 114.47 & 81.20 & 105.09 & 74.50 & 119.95 & 67.20 & 113.75 & 63.70 \\
\hline GLU & B & 64 & 30.37 & 22.50 & 32.36 & 24.00 & 31.01 & 18.00 & 32.77 & 19.00 \\
\hline LEU & B & 65 & 0.02 & 0.00 & 0.28 & 0.20 & 0.02 & 0.00 & 0.28 & 0.20 \\
\hline
\end{tabular}




\begin{tabular}{|c|c|c|c|c|c|c|c|c|c|c|}
\hline ALA & B & 66 & 27.71 & 39.90 & 22.63 & 32.60 & 41.56 & 38.50 & 33.80 & 31.30 \\
\hline ASP & B & 67 & 78.11 & 76.10 & 77.37 & 75.30 & 86.95 & 61.90 & 88.11 & 62.80 \\
\hline TYR & B & 68 & 18.42 & 10.40 & 12.14 & 6.80 & 18.96 & 8.90 & 12.28 & 5.80 \\
\hline ASP & B & 69 & 33.84 & 33.00 & 29.85 & 29.10 & 35.42 & 25.20 & 31.23 & 22.20 \\
\hline ALA & B & 70 & 0.00 & 0.00 & 0.00 & 0.00 & 0.00 & 0.00 & 0.00 & 0.00 \\
\hline ILE & B & 71 & 0.00 & 0.00 & 0.00 & 0.00 & 0.00 & 0.00 & 0.00 & 0.00 \\
\hline ILE & B & 72 & 0.00 & 0.00 & 0.00 & 0.00 & 0.00 & 0.00 & 0.00 & 0.00 \\
\hline PHE & B & 73 & 0.15 & 0.10 & 1.80 & 1.10 & 0.15 & 0.10 & 1.80 & 0.90 \\
\hline GLY & B & 74 & 0.00 & 0.00 & 0.00 & 0.00 & 0.00 & 0.00 & 0.00 & 0.00 \\
\hline THR & B & 75 & 0.24 & 0.20 & 0.30 & 0.30 & 0.24 & 0.20 & 0.30 & 0.20 \\
\hline PRO & B & 76 & 1.44 & 1.20 & 0.00 & 0.00 & 1.44 & 1.10 & 0.00 & 0.00 \\
\hline THR & B & 77 & 0.00 & 0.00 & 0.00 & 0.00 & 7.97 & 5.70 & 0.00 & 0.00 \\
\hline ARG & B & 78 & 87.11 & 43.30 & 6.17 & 3.10 & 90.65 & 38.00 & 6.17 & 2.60 \\
\hline PHE & B & 79 & 44.44 & 27.10 & 3.70 & 2.30 & 45.19 & 22.70 & 3.70 & 1.90 \\
\hline GLY & B & 80 & 0.28 & 0.90 & 0.00 & 0.00 & 1.55 & 1.90 & 0.00 & 0.00 \\
\hline ASN & B & 81 & 16.29 & 15.30 & 0.64 & 0.60 & 16.29 & 11.30 & 0.64 & 0.40 \\
\hline MET & B & 82 & 0.14 & 0.10 & 0.22 & 0.10 & 6.90 & 3.60 & 0.22 & 0.10 \\
\hline SER & B & 83 & 4.01 & 5.10 & 0.00 & 0.00 & 4.01 & 3.40 & 0.00 & 0.00 \\
\hline GLY & B & 84 & 7.88 & 24.40 & 0.89 & 2.80 & 10.75 & 13.40 & 0.89 & 1.10 \\
\hline GLN & B & 85 & 31.14 & 22.10 & 9.49 & 6.70 & 32.87 & 18.40 & 10.76 & 6.00 \\
\hline MET & B & 86 & 0.11 & 0.10 & 0.38 & 0.20 & 0.11 & 0.10 & 0.38 & 0.20 \\
\hline ARG & B & 87 & 4.02 & 2.00 & 0.52 & 0.30 & 4.02 & 1.70 & 0.52 & 0.20 \\
\hline THR & B & 88 & 40.69 & 40.00 & 24.15 & 23.70 & 40.69 & 29.20 & 24.40 & 17.50 \\
\hline PHE & B & 89 & 4.13 & 2.50 & 4.70 & 2.90 & 4.54 & 2.30 & 5.12 & 2.60 \\
\hline LEU & B & 90 & 1.66 & 1.20 & 3.54 & 2.50 & 1.73 & 1.00 & 3.54 & 2.00 \\
\hline ASP & B & 91 & 14.41 & 14.00 & 8.49 & 8.30 & 17.95 & 12.80 & 20.09 & 14.30 \\
\hline GLN & B & 92 & 99.79 & 70.80 & 91.28 & 64.70 & 114.64 & 64.20 & 99.21 & 55.60 \\
\hline THR & B & 93 & 0.72 & 0.70 & 0.19 & 0.20 & 0.72 & 0.50 & 0.19 & 0.10 \\
\hline GLY & B & 94 & 12.91 & 39.90 & 18.35 & 56.80 & 21.50 & 26.80 & 26.68 & 33.30 \\
\hline GLY & B & 95 & 40.29 & 124.60 & 37.35 & 115.50 & 58.58 & 73.10 & 57.52 & 71.80 \\
\hline LEU & B & 96 & 17.81 & 12.60 & 8.54 & 6.10 & 20.06 & 11.20 & 8.60 & 4.80 \\
\hline TRP & B & 97 & 82.17 & 38.90 & 76.99 & 36.40 & 83.13 & 33.30 & 86.52 & 34.70 \\
\hline ALA & B & 98 & 46.58 & 67.10 & 49.69 & 71.60 & 69.19 & 64.10 & 81.25 & 75.30 \\
\hline SER & B & 99 & 57.34 & 73.40 & 54.88 & 70.30 & 83.25 & 71.50 & 84.65 & 72.70 \\
\hline GLY & B & 100 & 5.00 & 15.50 & 24.71 & 76.40 & 16.96 & 21.20 & 38.14 & 47.60 \\
\hline ALA & B & 101 & 19.24 & 27.70 & 23.85 & 34.40 & 28.08 & 26.00 & 30.99 & 28.70 \\
\hline LEU & B & 102 & 1.04 & 0.70 & 2.85 & 2.00 & 1.20 & 0.70 & 3.40 & 1.90 \\
\hline TYR & B & 103 & 32.07 & 18.10 & 45.94 & 25.90 & 50.89 & 23.90 & 63.73 & 30.00 \\
\hline GLY & B & 104 & 8.60 & 26.60 & 9.27 & 28.70 & 19.59 & 24.50 & 24.90 & 31.10 \\
\hline LYS & B & 105 & 34.29 & 21.00 & 42.58 & 26.10 & 34.29 & 17.10 & 42.58 & 21.20 \\
\hline LEU & B & 106 & 2.02 & 1.40 & 2.58 & 1.80 & 2.06 & 1.20 & 2.65 & 1.50 \\
\hline ALA & B & 107 & 0.32 & 0.50 & 0.00 & 0.00 & 0.81 & 0.70 & 0.00 & 0.00 \\
\hline SER & B & 108 & 0.09 & 0.10 & 0.00 & 0.00 & 0.09 & 0.10 & 0.00 & 0.00 \\
\hline VAL & B & 109 & 0.07 & 0.10 & 0.00 & 0.00 & 0.07 & 0.00 & 0.00 & 0.00 \\
\hline PHE & B & 110 & 0.00 & 0.00 & 0.00 & 0.00 & 0.00 & 0.00 & 0.00 & 0.00 \\
\hline
\end{tabular}




\begin{tabular}{|c|c|c|c|c|c|c|c|c|c|c|}
\hline SER & B & 111 & 0.00 & 0.00 & 0.00 & 0.00 & 0.00 & 0.00 & 0.00 & 0.00 \\
\hline SER & B & 112 & 3.48 & 4.50 & 0.00 & 0.00 & 3.48 & 3.00 & 0.00 & 0.00 \\
\hline THR & B & 113 & 21.99 & 21.60 & 0.09 & 0.10 & 32.14 & 23.10 & 0.39 & 0.30 \\
\hline GLY & B & 114 & 11.53 & 35.70 & 10.02 & 31.00 & 21.84 & 27.30 & 11.08 & 13.80 \\
\hline THR & B & 115 & 63.55 & 62.50 & 70.18 & 69.00 & 72.36 & 52.00 & 102.41 & 73.50 \\
\hline GLY & B & 116 & 5.15 & 15.90 & 13.43 & 41.50 & 14.90 & 18.60 & 16.89 & 21.10 \\
\hline GLY & B & 117 & 12.30 & 38.10 & 6.90 & 21.30 & 14.57 & 18.20 & 10.56 & 13.20 \\
\hline GLY & B & 118 & 1.15 & 3.60 & 0.00 & 0.00 & 1.20 & 1.50 & 0.00 & 0.00 \\
\hline GLN & B & 119 & 38.98 & 27.60 & 21.30 & 15.10 & 39.27 & 22.00 & 21.30 & 11.90 \\
\hline GLU & B & 120 & 26.94 & 20.00 & 5.24 & 3.90 & 27.53 & 16.00 & 5.24 & 3.00 \\
\hline GLN & B & 121 & 17.47 & 12.40 & 15.00 & 10.60 & 18.97 & 10.60 & 15.00 & 8.40 \\
\hline THR & B & 122 & 0.00 & 0.00 & 0.00 & 0.00 & 0.00 & 0.00 & 0.00 & 0.00 \\
\hline ILE & B & 123 & 0.00 & 0.00 & 0.00 & 0.00 & 0.00 & 0.00 & 0.00 & 0.00 \\
\hline THR & B & 124 & 18.01 & 17.70 & 15.94 & 15.70 & 22.41 & 16.10 & 22.21 & 16.00 \\
\hline SER & B & 125 & 19.22 & 24.60 & 9.82 & 12.60 & 21.01 & 18.00 & 9.94 & 8.50 \\
\hline THR & B & 126 & 0.14 & 0.10 & 0.32 & 0.30 & 0.14 & 0.10 & 0.32 & 0.20 \\
\hline TRP & B & 127 & 2.58 & 1.20 & 4.50 & 2.10 & 2.58 & 1.00 & 4.50 & 1.80 \\
\hline THR & B & 128 & 9.16 & 9.00 & 4.81 & 4.70 & 9.16 & 6.60 & 5.00 & 3.60 \\
\hline THR & B & 129 & 1.19 & 1.20 & 0.17 & 0.20 & 1.19 & 0.90 & 0.17 & 0.10 \\
\hline LEU & B & 130 & 0.39 & 0.30 & 1.80 & 1.30 & 0.39 & 0.20 & 1.80 & 1.00 \\
\hline ALA & B & 131 & 0.00 & 0.00 & 0.00 & 0.00 & 0.00 & 0.00 & 0.00 & 0.00 \\
\hline HIS & B & 132 & 8.70 & 5.90 & 0.08 & 0.10 & 9.56 & 5.20 & 1.15 & 0.60 \\
\hline HIS & B & 133 & 4.04 & 2.70 & 5.65 & 3.80 & 7.44 & 4.10 & 9.80 & 5.40 \\
\hline GLY & B & 134 & 0.00 & 0.00 & 0.00 & 0.00 & 0.04 & 0.10 & 0.05 & 0.10 \\
\hline MET & B & 135 & 0.00 & 0.00 & 0.85 & 0.50 & 0.00 & 0.00 & 0.85 & 0.40 \\
\hline VAL & B & 136 & 2.99 & 2.60 & 2.33 & 2.00 & 2.99 & 2.00 & 2.33 & 1.50 \\
\hline ILE & B & 137 & 0.15 & 0.10 & 0.00 & 0.00 & 0.15 & 0.10 & 0.00 & 0.00 \\
\hline VAL & B & 138 & 0.00 & 0.00 & 0.00 & 0.00 & 0.00 & 0.00 & 0.00 & 0.00 \\
\hline PRO & B & 139 & 0.00 & 0.00 & 0.01 & 0.00 & 0.11 & 0.10 & 0.01 & 0.00 \\
\hline ILE & B & 140 & 8.10 & 5.90 & 9.61 & 7.00 & 8.21 & 4.70 & 10.57 & 6.00 \\
\hline GLY & B & 141 & 0.00 & 0.00 & 0.00 & 0.00 & 6.31 & 7.90 & 5.67 & 7.10 \\
\hline TYR & B & 142 & 57.39 & 32.40 & 60.44 & 34.10 & 87.93 & 41.30 & 115.23 & 54.20 \\
\hline ALA & B & 143 & 32.81 & 47.30 & N/A & N/A & 87.74 & 81.30 & N/A & N/A \\
\hline ALA & B & 144 & N/A & N/A & N/A & N/A & N/A & N/A & N/A & N/A \\
\hline GLN & B & 145 & N/A & N/A & N/A & N/A & N/A & N/A & N/A & N/A \\
\hline GLU & B & 146 & N/A & N/A & N/A & N/A & N/A & N/A & N/A & N/A \\
\hline LEU & B & 147 & N/A & N/A & N/A & N/A & $\mathrm{N} / \mathrm{A}$ & N/A & N/A & N/A \\
\hline PHE & B & 148 & N/A & N/A & $\mathrm{N} / \mathrm{A}$ & $\mathrm{N} / \mathrm{A}$ & N/A & $\mathrm{N} / \mathrm{A}$ & N/A & N/A \\
\hline ASP & B & 149 & N/A & N/A & N/A & N/A & N/A & N/A & N/A & N/A \\
\hline VAL & B & 150 & N/A & N/A & $\mathrm{N} / \mathrm{A}$ & $\mathrm{N} / \mathrm{A}$ & N/A & N/A & N/A & N/A \\
\hline SER & $B$ & 151 & N/A & N/A & $\mathrm{N} / \mathrm{A}$ & $\mathrm{N} / \mathrm{A}$ & N/A & N/A & N/A & $\mathrm{N} / \mathrm{A}$ \\
\hline GLN & $B$ & 152 & N/A & N/A & $\mathrm{N} / \mathrm{A}$ & $\mathrm{N} / \mathrm{A}$ & N/A & N/A & N/A & N/A \\
\hline VAL & $B$ & 153 & N/A & N/A & $\mathrm{N} / \mathrm{A}$ & N/A & N/A & N/A & N/A & N/A \\
\hline ARG & B & 154 & N/A & N/A & $\mathrm{N} / \mathrm{A}$ & $\mathrm{N} / \mathrm{A}$ & $\mathrm{N} / \mathrm{A}$ & N/A & N/A & $\mathrm{N} / \mathrm{A}$ \\
\hline GLY & B & 155 & N/A & N/A & N/A & N/A & N/A & N/A & N/A & N/A \\
\hline
\end{tabular}




\begin{tabular}{|c|c|c|c|c|c|c|c|c|c|c|}
\hline GLY & B & 156 & 26.50 & 82.00 & 29.76 & 92.10 & 89.00 & 111.10 & 74.96 & 93.60 \\
\hline THR & B & 157 & 1.72 & 1.70 & 2.00 & 2.00 & 12.75 & 9.20 & 10.05 & 7.20 \\
\hline PRO & B & 158 & 0.41 & 0.30 & 0.08 & 0.10 & 0.52 & 0.40 & 0.16 & 0.10 \\
\hline TYR & B & 159 & 0.61 & 0.30 & 0.00 & 0.00 & 0.61 & 0.30 & 0.00 & 0.00 \\
\hline GLY & B & 160 & 0.00 & 0.00 & 0.00 & 0.00 & 0.64 & 0.80 & 0.38 & 0.50 \\
\hline ALA & B & 161 & 0.54 & 0.80 & 1.06 & 1.50 & 0.54 & 0.50 & 1.06 & 1.00 \\
\hline THR & B & 162 & 7.06 & 6.90 & 4.35 & 4.30 & 14.92 & 10.70 & 11.67 & 8.40 \\
\hline THR & B & 163 & 0.29 & 0.30 & 1.42 & 1.40 & 1.48 & 1.10 & 1.67 & 1.20 \\
\hline ILE & B & 164 & 134.06 & 97.20 & 53.39 & 38.70 & 148.59 & 84.80 & 74.50 & 42.50 \\
\hline ALA & B & 165 & 1.95 & 2.80 & 26.86 & 38.70 & 27.28 & 25.30 & 34.72 & 32.20 \\
\hline GLY & B & 166 & N/A & N/A & 17.89 & 55.30 & N/A & N/A & 102.42 & 127.90 \\
\hline GLY & B & 167 & N/A & $\mathrm{N} / \mathrm{A}$ & $\mathrm{N} / \mathrm{A}$ & N/A & $\mathrm{N} / \mathrm{A}$ & $\mathrm{N} / \mathrm{A}$ & $\mathrm{N} / \mathrm{A}$ & $\mathrm{N} / \mathrm{A}$ \\
\hline ASP & B & 168 & $\mathrm{~N} / \mathrm{A}$ & $\mathrm{N} / \mathrm{A}$ & $\mathrm{N} / \mathrm{A}$ & N/A & $\mathrm{N} / \mathrm{A}$ & $\mathrm{N} / \mathrm{A}$ & $\mathrm{N} / \mathrm{A}$ & $\mathrm{N} / \mathrm{A}$ \\
\hline GLY & B & 169 & N/A & N/A & N/A & N/A & N/A & $\mathrm{N} / \mathrm{A}$ & $\mathrm{N} / \mathrm{A}$ & $\mathrm{N} / \mathrm{A}$ \\
\hline SER & B & 170 & N/A & N/A & N/A & N/A & $\mathrm{N} / \mathrm{A}$ & $\mathrm{N} / \mathrm{A}$ & N/A & N/A \\
\hline ARG & B & 171 & N/A & N/A & N/A & N/A & $\mathrm{N} / \mathrm{A}$ & $\mathrm{N} / \mathrm{A}$ & $\mathrm{N} / \mathrm{A}$ & $\mathrm{N} / \mathrm{A}$ \\
\hline GLN & B & 172 & 136.48 & 96.80 & 62.99 & 44.70 & 170.56 & 95.60 & 121.49 & 68.10 \\
\hline PRO & B & 173 & 4.90 & 4.10 & 3.03 & 2.50 & 18.46 & 13.60 & 15.59 & 11.40 \\
\hline SER & B & 174 & 49.48 & 63.30 & 52.92 & 67.80 & 49.54 & 42.50 & 54.07 & 46.40 \\
\hline GLN & B & 175 & 124.70 & 88.40 & 148.82 & 105.60 & 132.16 & 74.00 & 157.30 & 88.10 \\
\hline GLU & B & 176 & 128.40 & 95.30 & 84.40 & 62.60 & 131.46 & 76.30 & 85.66 & 49.70 \\
\hline GLU & B & 177 & 27.39 & 20.30 & 30.45 & 22.60 & 27.44 & 15.90 & 30.47 & 17.70 \\
\hline LEU & B & 178 & 20.34 & 14.40 & 33.24 & 23.60 & 20.34 & 11.40 & 33.24 & 18.60 \\
\hline SER & B & 179 & 48.77 & 62.40 & 45.35 & 58.10 & 52.95 & 45.50 & 51.57 & 44.30 \\
\hline ILE & B & 180 & 68.09 & 49.40 & 71.26 & 51.70 & 68.09 & 38.90 & 71.26 & 40.70 \\
\hline ALA & B & 181 & 0.00 & 0.00 & 0.00 & 0.00 & 0.00 & 0.00 & 0.00 & 0.00 \\
\hline ARG & B & 182 & 77.72 & 38.60 & 71.50 & 35.50 & 78.36 & 32.80 & 71.87 & 30.10 \\
\hline TYR & B & 183 & 64.66 & 36.50 & 88.64 & 50.00 & 65.31 & 30.70 & 89.28 & 42.00 \\
\hline GLN & B & 184 & 0.00 & 0.00 & 0.00 & 0.00 & 0.00 & 0.00 & 0.00 & 0.00 \\
\hline GLY & B & 185 & 0.00 & 0.00 & 0.00 & 0.00 & 0.00 & 0.00 & 0.00 & 0.00 \\
\hline GLU & B & 186 & 73.56 & 54.60 & 67.80 & 50.30 & 75.45 & 43.80 & 69.40 & 40.30 \\
\hline TYR & B & 187 & 37.74 & 21.30 & 34.34 & 19.40 & 38.87 & 18.30 & 35.34 & 16.60 \\
\hline VAL & B & 188 & 0.00 & 0.00 & 0.00 & 0.00 & 0.00 & 0.00 & 0.00 & 0.00 \\
\hline ALA & B & 189 & 0.00 & 0.00 & 0.00 & 0.00 & 0.00 & 0.00 & 0.00 & 0.00 \\
\hline GLY & B & 190 & 18.85 & 58.30 & 18.42 & 57.00 & 28.80 & 36.00 & 22.18 & 27.70 \\
\hline LEU & B & 191 & 17.28 & 12.20 & 15.02 & 10.60 & 18.42 & 10.30 & 15.87 & 8.90 \\
\hline ALA & B & 192 & 0.00 & 0.00 & 0.00 & 0.00 & 0.00 & 0.00 & 0.00 & 0.00 \\
\hline VAL & B & 193 & 31.49 & 27.60 & 31.34 & 27.40 & 36.84 & 24.30 & 35.05 & 23.10 \\
\hline LYS & B & 194 & 110.50 & 67.70 & 110.25 & 67.50 & 127.15 & 63.30 & 130.92 & 65.20 \\
\hline LEU & B & 195 & 8.28 & 5.90 & 14.30 & 10.10 & 16.67 & 9.30 & 37.41 & 20.90 \\
\hline ASN & B & 196 & 36.99 & 34.80 & 48.99 & 46.10 & 75.69 & 52.60 & 80.88 & 56.20 \\
\hline GLY & B & 197 & 32.56 & 100.70 & 35.32 & 109.20 & 55.23 & 69.00 & 70.23 & 87.70 \\
\hline
\end{tabular}

